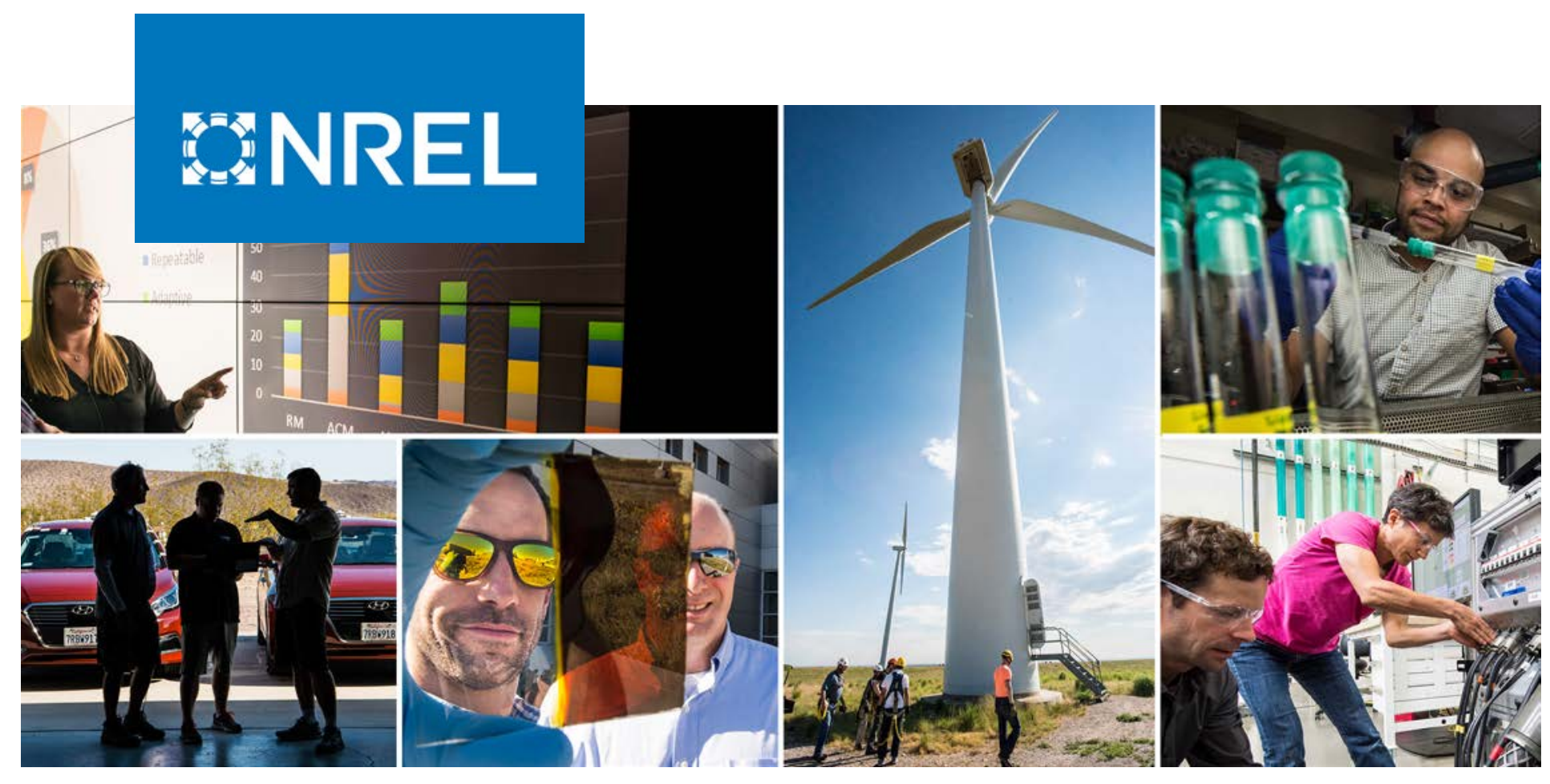

\title{
Addressing Soiling: From Interface Chemistry to Practicality
}

Lin Simpson

National Renewable Energy Laboratory

NREL is a national laboratory of the U.S. Department of Energy

Office of Energy Efficiency \& Renewable Energy

Operated by the Alliance for Sustainable Energy, LLC

This report is available at no cost from the National Renewable Energy Laboratory (NREL) at www.nrel.gov/publications.

\section{Technical Report}

NREL/TP-5K00-72853

March 2020 


\section{GNREL}

\section{Addressing Soiling: From Interface Chemistry to Practicality}

\section{Lin Simpson}

National Renewable Energy Laboratory

\section{Suggested Citation}

Simpson, Lin. 2020. Addressing Soiling: From Interface Chemistry to Practicality. Golden, CO: National Renewable Energy Laboratory. NREL/TP-5K00-72853.

https://www.nrel.gov/docs/fy20osti/72853.pdf.

NREL is a national laboratory of the U.S. Department of Energy Office of Energy Efficiency \& Renewable Energy Operated by the Alliance for Sustainable Energy, LLC

This report is available at no cost from the National Renewable Energy Laboratory (NREL) at www.nrel.gov/publications.

Contract No. DE-AC36-08GO28308
Technical Report NREL/TP-5K00-72853 March 2020

National Renewable Energy Laboratory 15013 Denver West Parkway Golden, CO 80401 303-275-3000 • www.nrel.gov 


\section{NOTICE}

This work was authored by the National Renewable Energy Laboratory, operated by Alliance for Sustainable Energy, LLC, for the U.S. Department of Energy (DOE) under Contract No. DE-AC36-08GO28308. Funding provided by U.S. Department of Energy Office of Energy Efficiency and Renewable Energy, Solar Energy Technologies Office SuNLaMP program. The views expressed herein do not necessarily represent the views of the DOE or the U.S. Government.

This report is available at no cost from the National Renewable Energy Laboratory (NREL) at www.nrel.gov/publications.

U.S. Department of Energy (DOE) reports produced after 1991 and a growing number of pre-1991 documents are available free via www.OSTI.gov.

Cover Photos by Dennis Schroeder: (clockwise, left to right) NREL 51934, NREL 45897, NREL 42160, NREL 45891, NREL 48097, NREL 46526.

NREL prints on paper that contains recycled content. 


\section{Acknowledgments}

This work was authored in part by the National Renewable Energy Laboratory, operated by Alliance for Sustainable Energy, LLC, for the U.S. Department of Energy (DOE) under Contract No. DE-AC36-08GO28308. Funding provided by U.S. Department of Energy Office of Energy Efficiency and Renewable Energy, Solar Energy Technologies Office SuNLaMP program. The views expressed in the article do not necessarily represent the views of the DOE or the U.S. Government. The U.S. Government retains and the publisher, by accepting the article for publication, acknowledges that the U.S. Government retains a nonexclusive, paid-up, irrevocable, worldwide license to publish or reproduce the published form of this work, or allow others to do so, for U.S. Government purposes. 


\section{List of Acronyms}

$\begin{array}{ll}\text { AFM } & \text { atomic force microscopy } \\ \text { AR } & \text { anti-reflection } \\ \text { AS } & \text { anti-soiling } \\ \text { CSP } & \text { concentrating solar power } \\ \text { DOE } & \text { U.S. Department of Energy } \\ \text { ETL } & \text { extract transform and load } \\ \text { FRP } & \text { fixed rate and precipitation } \\ \text { LCOE } & \text { levelized cost of electricity } \\ \text { MSD } & \text { mean signed deviation } \\ \text { NREL } & \text { National Renewable Energy Laboratory } \\ \text { NSRDB } & \text { National Solar Radiation Database } \\ \text { O\&M } & \text { operating and maintenance } \\ \text { PID } & \text { potential-induced degradation } \\ \text { PM } & \text { performance metric, also, particulate matter } \\ \text { PV } & \text { photovoltaic } \\ \text { PVQAT } & \text { International Photovoltaic Quality Assurance Task Force } \\ \text { QCM } & \text { quartz-crystal microbalance } \\ \text { RH } & \text { relative humidity } \\ \text { RMSE } & \text { root-mean-square error } \\ \text { SRR } & \text { stochastic rate and recovery }\end{array}$




\section{Executive Summary}

Natural soiling has reduced the energy output of photovoltaic (PV) systems since the technology was first used. Projecting even a small average annual soiling loss translates to billions of dollars in annual lost revenue worldwide. ${ }^{1}$ Production losses due to soiling can be very high in some locations, substantially increasing the levelized cost of electricity (LCOE) due to lost power production, increased operating and maintenance costs, and/or increased finance cost due to the uncertainty. Furthermore, although soiling has been discussed in the literature for more than 70 years, solutions to many problems are still needed. The National Renewable Energy Laboratory (NREL) is working with the PV industry to develop the tools/knowledge so that the effects of soiling can be predicted for different environmental conditions and cost-effective mitigation can be implemented. For this project, NREL performed a number of research and development tasks/subtasks in the following general areas to 1) predict PV module soiling losses based on environmental factors at a PV installation and from its energy production data, 2) quantitatively measure the adhesion forces to understand the physics enabling soiling, and 3) develop related standards on PV module coatings and artificial soiling. At the inception of the project, the PV industry considered these efforts to be the most important and immediate soiling issues that we could address to have the highest impact on LCOE. These focused efforts have led to outstanding accomplishments that have been communicated and very well received by the community.

To help decrease the uncertainty — and thus, costs — of soiling loss at specific sites, NREL has developed novel protocols to accurately extract soiling losses from PV production data ${ }^{2}$ and to predict soiling losses at new sites from soiling loss data and environmental factors. ${ }^{3}$ The ability to determine soiling loss from production data reduces or eliminates the need for soiling stations at a PV installation. Effectively, any PV installation can also be used to determine soiling losses. These analyses have been used to help build a "soiling" map that is available on the NREL website (www.nrel.gov/pv/soiling.html) and can be used by project engineers and finance groups to get a more accurate measure of soiling at a potential PV installation site. NREL has used soiling station data to identify the most important environmental factors that are correlated with average soiling losses and is using this information to develop models that accurately extrapolate and/or predict soiling losses at prospective sites without the need for local soiling stations.

NREL's investigations of soiling adhesion has several substantive conclusions. For example, dust adhesion is typically lower than expected and does not increase with increasing particle diameter because natural dust has rough surfaces that along with rough PV surfaces substantially reduce contact area. This result explains why larger particles, which effectively have the same contact area and thus adhesion force as smaller particles, are more easily blown off the PV modules than smaller particles with lower shear forces from the wind. Surface roughness (not surface energy) also appears to be the dominant factor in capillary adhesion resulting from thin layers of water on the module surface due to humidity in the air. This may address many of the contradictory published results and why both hydrophobic and hydrophilic surface modifications appear to reduce initial soiling, in that often the surface modifications can result in rougher surfaces. Interestingly, rougher surfaces may increase the formation and adhesion of cemented materials and fungi growth. Ultimately, fungi may be a critical component of soiling that is often overlooked but may be very prevalent in humid places around the world. Certainly, the initial results from our outdoor test samples and veteran module examination that found fungi on PV 
modules around the world indicate that much more work is needed in this area. Finally, another overlooked aspect (along with potential-induced degradation of the modules) of the practice of operating PV arrays at voltages up to $1500 \mathrm{~V}$ is the demonstrated increase in dust attraction and dust adhesion that occurs even when the sun has set, and ultimately, it has been demonstrated to increase soiling losses. Ultimately, the goal of all this work is to help the community understand soiling processes sufficiently well enough to identify effective mitigation strategies that may include well-scheduled cleaning, improved/appropriate cleaning techniques, and perhaps the identification of useful surface properties.

For both cleaning and coatings, a set of procedures needs to be developed to help identify what type of PV module degradation can be expected in actual field operations. Thus, for this project, NREL started the arduous process of identifying the available appropriate knowledge and plans for obtaining the other required information to establish a standard set of test conditions that can be used to qualify coatings and cleaning practices that may be used in conjunction with PV modules. After a thorough literature review, NREL identified several appropriate test standards that might be adaptable for use with PV modules and started modifying these tests as needed to produce results similar to those seen from field samples and veteran modules. In addition, NREL worked with industrial partners to obtain a diverse set of potential PV coatings on PV glass samples that were then fielded at different partner sites around the world. These samples were systematically cleaned in one of four methods, and samples are being returned to NREL every year for five years. These field samples and veteran modules provide the information needed to develop the laboratory tests that will be used to qualify the durability needed for coatings. In addition, NREL partners at Arizona State University have been developing artificial soiling and cleaning procedures that will be used as the basis for a coating efficacy standard.

Initial results from field coupons and veteran modules have identified several interesting findings that require additional investigations. For example, despite the high temperatures associated with PV modules and the glass coupons with black backing, fungi was observed on many samples from many different places around the world. The fungi growth on PV modules appears to be correlated with higher humidity and/or water levels, does not appear to be removed with simple rain events, and may be responsible for energy loss throughout the United States and world ranging from less than a couple of percent to perhaps more than 10\%. NREL has developed optical microscope imaging analysis that quantifies the amount of soiling from fungi versus other "dust" on a sample surface so that more detailed evaluations can be performed on PV modules to quantify the overall energy loss due to fungi throughout the United States. Another key result was that monthly dry brushing caused substantial damage to even very hard coatings in high dust regions. This suggests that cleaning schedules and/or technique may need to be adjusted based on the environment, amount of soiling, and/or coating. Finally, initial accelerated tests identified that although nylon may be durable, it may also induce more damage, compared with other common bristle materials (e.g., polyester and hog bristle) used in the glass-cleaning industry.

By providing a detailed understanding of soiling mechanisms and the corresponding standards /requirements for PV module coatings, NREL is providing valuable information for the PV community to help develop effective and/or durable soiling mitigation technologies. In addition, by providing the community with methodologies to more accurately measure and/or predict soiling loss at a specific site, NREL is helping to reduce uncertainty in PV production. By 
reducing the uncertainty, operating and maintenance costs, and module costs - while increasing PV plant power output - this project achieved its primary goal of reducing PV LCOE. 


\section{Table of Contents}

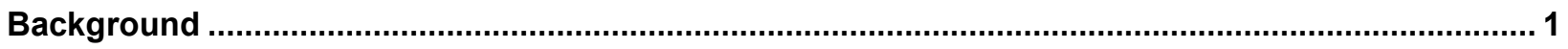

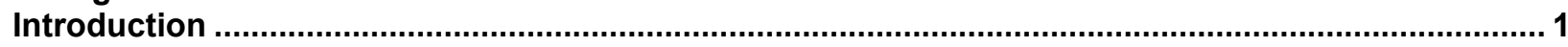

Project Results and Discussion ................................................................................................... 2

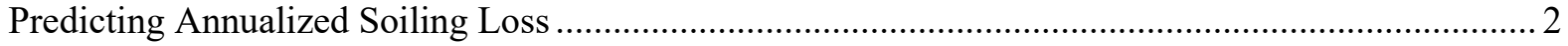

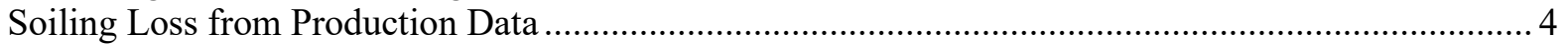

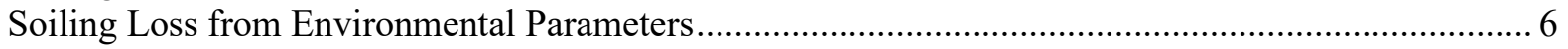

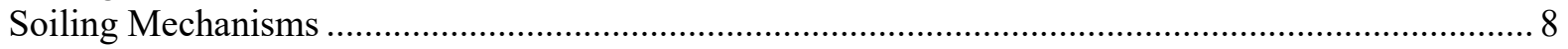

Initial Soiling Adhesion ...................................................................................... 8

Electric-Field-Induced Soiling (Particle Attraction and Adhesion) ......................................9

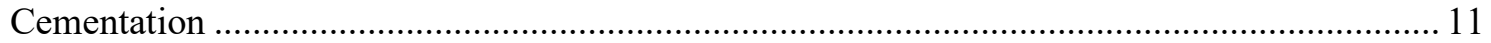

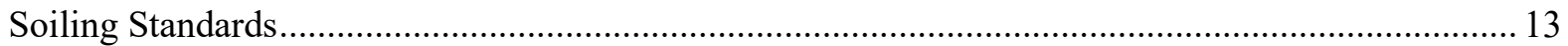

Evidence from Field Samples and Veteran Modules ........................................................ 13

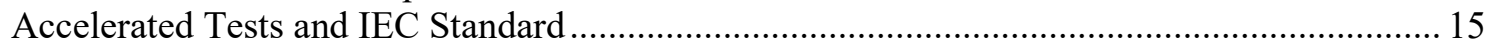

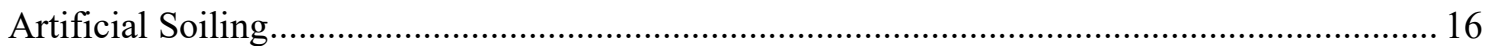

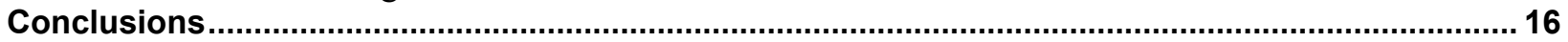

Budget and Schedule ................................................................................................................ 17

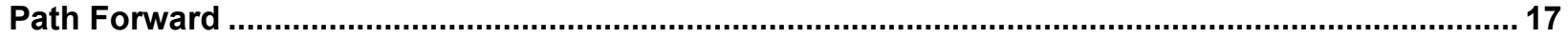

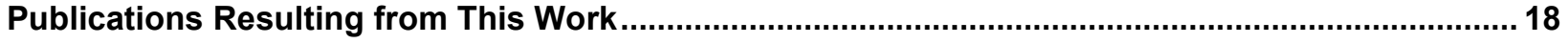

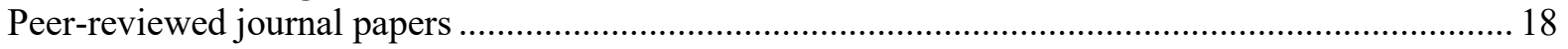

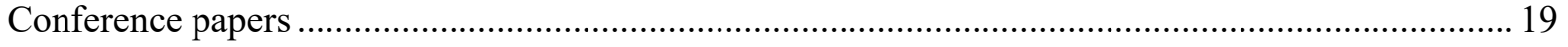

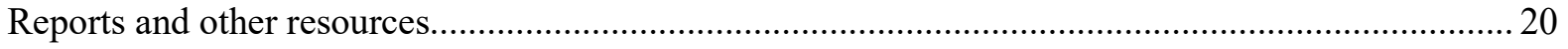

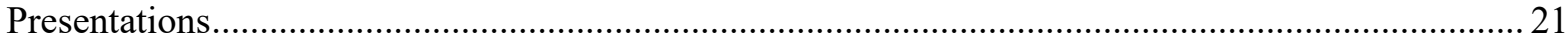

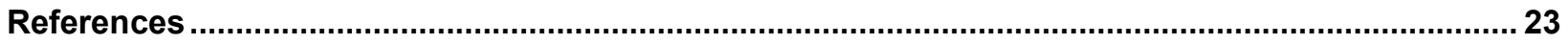




\section{List of Figures}

Figure 1. The steps of the stochastic rate and recovery method. (a) Positive shifts in a moving median of daily performance metric (PM) are automatically detected and classified as cleaning events. This divides the time series into soiling intervals. (b) Each soiling interval is analyzed with the Theil Sen regression method to extract the slope (soiling rate) and uncertainty in the slope. (c) The uncertainty of each soiling interval is used in a Monte Carlo simulation to quantify the effect of possible soiling intervals that explain the data. (d) The resulting distribution in soiling losses is analyzed for median and confidence interval. ....................... 4

Figure 2. Screen shot of NREL soiling map.

Figure 3. Parameters with the highest coefficients of determination and p-values $<0.05$ when related to the soiling ratio of the 20 soiling stations investigated in Micheli et al.

Figure 4. The root-mean-square errors and normalized root-mean-square errors obtained by comparing the actual soiling ratios with those predicted by using the significant linear correlations....... 7

Figure 5. F-z curves for several dust particles as a function of relative humidity for two different surface roughness values. The insets show the scanning electron micrography images for two of the dust particles.

Figure 6. (a) AFM F-z curve at Vs $=-150 \mathrm{~V}$, (b) Fes measured on three dust particles with different sizes and shapes and on a silica sphere with diameter of $20 \mu \mathrm{m}$, (c) normalized Fes per unit area facing to the glass.

Figure 7. Image (above) and soiling loss comparison data (below) of PV modules in Riverside, CA. One module operated with no bias, whereas the other two were biased at $+1000 \mathrm{~V}$ and $-1000 \mathrm{~V}$. The ratio of the measured short-circuit currents are shown and indicate that the $-1000 \mathrm{~V}$ module is soiling faster than the $+1000 \mathrm{~V}$ module, which is soiling faster than the unbiased module.

Figure 8. QCM data demonstrating the onset of cementation of halite dust particles during cycling between dry and humid air.

Figure 9. Image of field samples (top) and graph of data (bottom) showing the percent area coverage (PAC) of field-aged glass coupons from Dubai as a function of coating and cleaning technique ( $\mathrm{DB}=$ dry brush, $\mathrm{WS}=$ water spray, and WSS = wet sponge and squeegee). The PAC of each coupon is calculated as the average of the PAC of five locations on the same coupon.

Figure 10. Correlation between area coverage by soiling and representative solar-weighted transmittance $\left(\tau_{\text {rsw }}\right)$ for uncoated glass $(\mathrm{J})$ samples from Dubai (red circles) and Mumbai (blue circles). The average baseline $\tau_{\text {rsw }}$ of uncoated glass $(\mathrm{J})$ was $91.2 \%$ (black circle, standard deviation was $\sim 0)$

\section{List of Tables}

Table I. Validation results comparing the stochastic rate and recovery (SRR) method developed here, and status quo fixed rate and precipitation (FRP) models with various rain thresholds and refractory periods. The coefficient of determination $\left(\mathrm{R}^{2}\right)$, root-mean-square error (RMSE), and mean signed deviation (MSD) are all shown. 


\section{Background}

Natural soiling has reduced the energy output of photovoltaic (PV) systems since the inception of the technology. As the National Renewable Energy Laboratory's (NREL's) comprehensive review of solar energy soiling documents, ${ }^{4}$ the issues have been discussed in the literature for more than 70 years - and yet, "the fundamental properties of dust and its effect on energy transfer are still not fully understood, nor is there a clear solution to the problem." Soiling, i.e., the accumulation of contaminants such as dust, particles, or dirt on the surface of PV modules affects PV modules worldwide. Soiling absorbs, reflects, and deflects sunlight, reducing the intensity that reaches the PV cell and thus, in turn, reducing the electricity produced. Power drops higher than $50 \%$ have been reported worldwide because of soiling, ${ }^{4}$ while losses up to $7 \%$ of the annual energy yield have been caused by soiling in the United States. ${ }^{5}$ Additional investigations found that often a substantial amount of rain is required to actually remove the soiling, and that without active washing, the PV energy output can be reduced $20 \%$ to $40 \%$ during typical weather conditions. ${ }^{6}$ Of course, sand storms can coat surfaces and reduce energy collection very rapidly. Furthermore, the most insolation-rich regions in the United States/world can have higher soiling losses, and some solar thermal plants need to be cleaned twice weekly. ${ }^{7}$ A flat 4\% soiling loss affecting all the PV capacity worldwide would lead to $\$ 2$ billion loss in revenue every year. ${ }^{8}$ On the other hand, cleaning a utility-scale PV system currently costs $\$ 0.20$ to $\$ 0.50$ per module, depending on the system size and location, and can be even more expensive for smaller commercial or domestic systems. Considering premium modules rated at $365 \mathrm{~W}$ and a cleaning cost of $\$ 0.20$ per module, a one-time cleaning of a $10-\mathrm{MW}$ system costs more than $\$ 5,000$. Therefore, it is important to monitor soiling in order to plan the most accurate cleaning schedule because cleaning non-soiled modules is an unnecessary expense, whereas not cleaning a soiled module is an avoidable energy and economic loss. Some of these issues may be resolved if coatings can be developed to increase light transmission (e.g., antireflecting coatings) and/or to decrease the amount of soiling that adheres (e.g., anti-soiling coatings) to the front surface of the modules. Substantial efforts to develop such coatings have been in progress for decades, but there is still very little understanding to guide coating development in terms of fundamental dust adhesion and of qualifying coatings in terms of efficacy and durability, especially in harsh soiling environments where corrosion and abrasion may substantially impact performance and degradation.

\section{Introduction}

To have maximum impact on the soiling problem, this project fully engaged U.S. PV and coating manufacturers to identify the most important problems that could be addressed within the threeyear effort. The overall goal of this project was to help reduce levelized cost of electricity (LCOE) in one of two ways. First, we developed methodologies/models that more accurately predict annualized soiling losses at new PV plant sites. These types of models reduce performance uncertainty, leading to lower finance rates and thus lower LCOE. Second, this project provided the PV industry with the necessary tools/knowledge for successful long-term deployment of modules with value-added coatings (e.g., antireflection and/or anti-soiling coatings). Such coatings target increased energy yield, leading to lower LCOE, but this can only be realized if the coating is appropriate for the installation environment and has the necessary long-term durability. 
NREL's team has taken a proactive approach to directly address some of the unresolved issues with soiling. To develop site evaluation tools, we used soiling station data, PV production data, and environmental data to identify critical criteria correlated with soiling losses. These highquality data came from hundreds of sites (well over $\$ 1.5$ million in cost share from partners such as First Solar, SunPower, and Cypress Creek) to produce accurate annualized soiling losses from production data and from models based on environmental parameters. These soiling loss results can then be used to determine operating and maintenance (O\&M) needs. These evaluations avoid the complexity of previous less successful attempts that tried to understand specific soiling events.

Complementary efforts developed industry-priority tools for value-added PV module coatings, involving: 1) deployment guidelines that are specific to the location and interface properties involved, and 2) international long-term durability standards. For example, surface roughness (not surface energy) was found to be the dominant factor associated with initial dust adhesion both in dry and humid conditions. Furthermore, humidity was a critical component creating more strongly adhered soiling (i.e., cementation), and the high voltages in modern utility and commercial arrays result in stronger dust attraction (i.e., higher soiling rates), stronger initial adhesion, and accelerated cementation. For the standards, the correlation between laboratory tests and field-observed degradation has required many "standard" test protocols to be substantially adjusted.

NREL's team used its expertise to identify and quantify the actual adhesion mechanisms/processes of soiling. This information is synergistic with the soiling loss modeling by providing information about which variables distinguish one location from another. This module surface property knowledge and soiling rate models are also important in developing coating durability standards that correlate accelerated laboratory test results with field degradation observations. Overall, this project used a technical plan that was industry-directed, achievable, and focused on directly impacting PV LCOE.

\section{Project Results and Discussion}

\section{Predicting Annualized Soiling Loss}

Present O\&M standards require PV systems to be monitored for soiling if annual soiling losses higher than $2 \%$ are expected, and the standards recommend multiple soiling detectors for any site greater than $5 \mathrm{MW} .{ }^{9}$ So far, the community has been monitoring soiling at PV sites mainly by using soiling stations. ${ }^{10,11}$ These systems are generally made of two PV devices (cells or modules), one of which is left to soil naturally while the other is regularly cleaned. Soiling is quantified by comparing the electrical outputs of the two PV devices. Soiling stations are cleaned either by an operator or through an automated rotating brush or high-pressurized water spray. As has been discussed, ${ }^{12}$ soiling stations require frequent cleanings and careful maintenance, which can be expensive; otherwise, their uncertainty can be even higher than the soiling measurement. In this light, innovative cleaning-less soiling stations have been presented and recently launched in the market to reduce the price and to limit the O\&M cost of soiling monitoring devices. ${ }^{13,14,15}$

Soiling extraction methods are an alternative to soiling stations to identify soiling trends directly from PV performance data. The first models presented in literature ${ }^{6,16}$ used the rainfall data and 
the soiling rate recorded during the longest dry period to estimate the yearly soiling losses at a number of sites in California. These models are simple and effective, but require the knowledge of the rainfall pattern (which might not always be available) and consider a fixed soiling rate for the whole data series (determined by a least-square regression of the longest soiling period). NREL investigations have shown that the soiling rate can vary with months, seasons, and years, ${ }^{17,18,19}$ leading to the requirement of new algorithms to better estimate soiling losses and soiling rates.

Being able to predict soiling losses at a new PV site would make it possible to include a more accurate soiling loss estimation in site cost-evaluation and selection and also to design the systems and O\&M plans to reduce the losses and minimize the costs. In addition, along with the loss in energy conversion, soiling causes an increase in the uncertainty of PV production, which leads to higher finance rates from investors. For all these reasons, when a new site is chosen for a PV installation, soiling stations are generally deployed first or soiling data from nearby sites are used to estimate the losses of the future plant. Soiling stations are the most common method to quantify soiling but require time to record enough data for an accurate estimation. On the other hand, soiling extraction algorithms are used if PV installations are available nearby, even if, before this project, no study had investigated how soiling varies among different sites depending on their distances. If PV performance and soiling data are lacking, environmental parameters could ideally be used to predict soiling at a new PV site because they are available for multiple years in many locations at no additional hardware cost. When the project started, studies had already discussed the relations between soiling, rainfall, and particulate matter, ${ }^{6,20}$ but no work had moved beyond site-specific soiling-loss analysis, investigating these relations in a systematic way for a large number of sites. 


\section{Soiling Loss from Production Data}

For this project, the NREL team developed a new, scalable approach for accurately quantifying soiling loss for the first time directly from PV yield timeseries data. Prior to this project, the status quo for quantifying soiling loss was based on fixed rate and precipitation threshold (FRP) models. ${ }^{6,16}$ These models rely on a single soiling rate, which is assumed to be known, and apply that rate between rain or cleaning events to generate a soiling profile. Such models can be useful, but the assumption of a constant and known soiling rate can be problematic. These models also require a precipitation threshold for cleaning and a refractory period (during which no soiling occurs after rain). These parameters may be site-dependent. The new
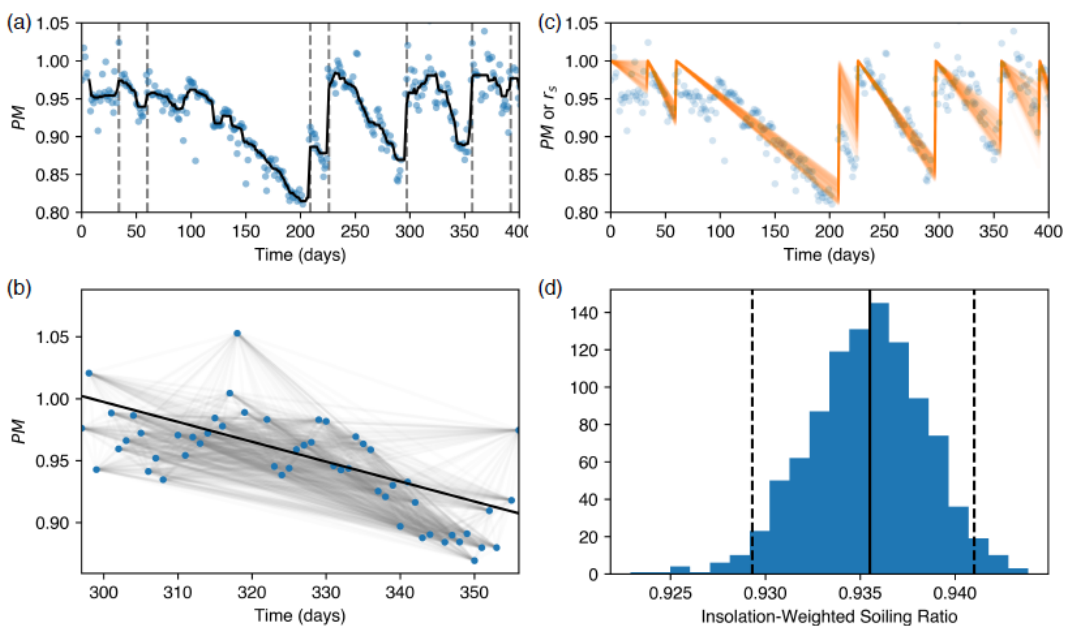

Figure 1. The steps of the stochastic rate and recovery method. (a) Positive shifts in a moving median of daily performance metric (PM) are automatically detected and classified as cleaning events. This divides the time series into soiling intervals. (b) Each soiling interval is analyzed with the Theil Sen regression method to extract the slope (soiling rate) and uncertainty in the slope. (c) The uncertainty of each soiling interval is used in a Monte Carlo simulation to quantify the effect of possible soiling intervals that explain the data. (d) The resulting distribution in soiling losses is analyzed for median and confidence interval. ${ }^{2}$ procedure does not require knowledge of a site-dependent soiling rate, a cleaning threshold, or precipitation data.

The procedure developed at NREL, termed stochastic rate and recovery (SRR), is based on the automated detection of cleaning events and an assessment of the soiling profiles and their uncertainty between cleaning events. In the final step, a Monte Carlo simulation is used to generate possible soiling loss profiles and assess uncertainty. The steps are illustrated in Figure 1 and described in detail. ${ }^{2}$ Key advantages are that it avoids site-dependent parameters and inherently captures the uncertainty in the irradiance-weighted soiling ratio. The SRR method was validated on 11 different soiling stations, where it outperformed FRP models across a range of statistical parameters, as shown in Table I. In addition, an early version of the SRR enabled NREL to quantify
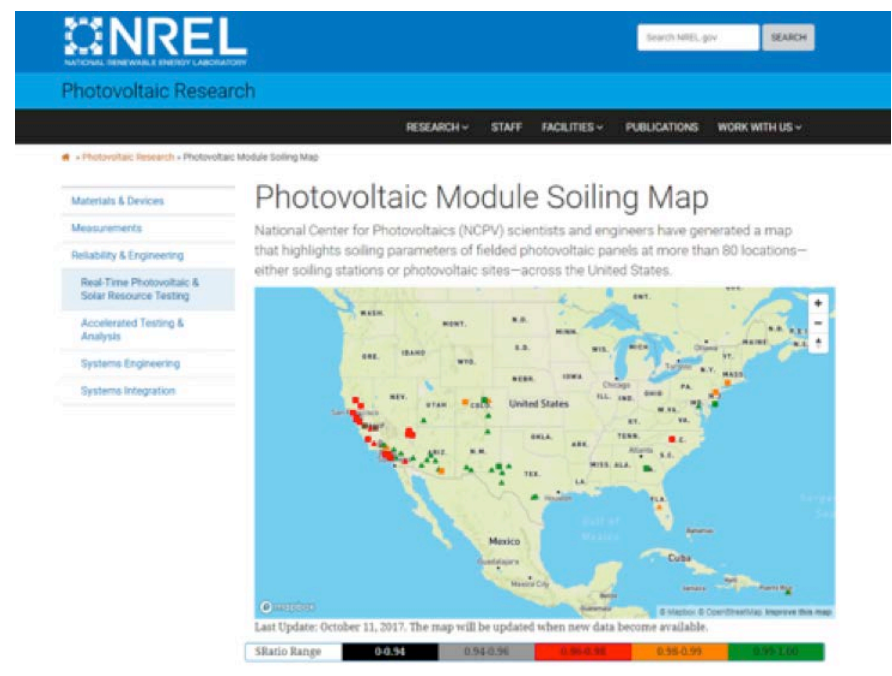

Figure 2. Screen shot of NREL soiling map. 
significant year-to-year variations in soiling loss. ${ }^{19}$ Finally, the SRR code has been made opensource and publicly available. ${ }^{21}$

As part of the Phase 2 Milestone, the model presented by Deceglie et al. ${ }^{2}$ and the other soiling extraction techniques developed by the NREL team during the project ${ }^{22,23}$ have been used to populate a map (Figure 2) of PV soiling, with data collected from PV systems and soiling stations installed in the United States. The map has been made available on the NREL website (www.nrel.gov/pv/soiling.html) and, in its first version, contains 83 data points ${ }^{5}$ and covers PVrelevant regions with diverse climates. The map will be updated as new locations become available. In addition, in agreement with our industrial partners, the time series of 19 soiling stations have been made available. ${ }^{24}$

The map is a useful tool to help investors and O\&M teams better estimate soiling losses. In this light, the ability to predict soiling at new PV sites by using soiling data from nearby locations has been investigated by Micheli et al. ${ }^{25}$ at NREL by employing different spatial interpolation techniques. This study showed average coefficients of determination as high as 0.74 , corresponding to a normalized root-mean-square error (RMSE) of $22.3 \%$ between the soiling measured at a number of sites with soiling stations and soiling estimated at the same sites by interpolating data measured at nearby soiling stations in the Southwest of the United States. These results were also enhanced, achieving normalized RMSE of $20.1 \%$ when a selectivesampling approach was employed to exclude from the analysis data points with dissimilar characteristics.

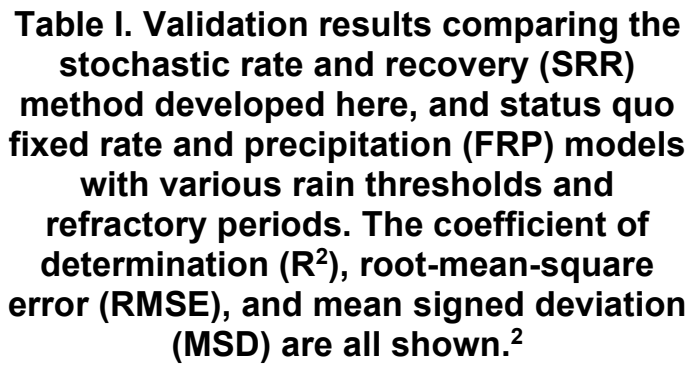

\begin{tabular}{lllll}
\hline \hline & Method & $R^{2}$ & RMSE & MSD \\
\hline 1 & SRR & 0.87 & 0.009 & -0.007 \\
2 & FRP: 0 mm, 3 day & 0.81 & 0.010 & 0.007 \\
3 & FRP: 0 mm 7 day & 0.80 & 0.012 & 0.009 \\
4 & FRP: 0 mm, 0 day & 0.80 & 0.009 & 0.005 \\
5 & FRP: $5 \mathrm{~mm}$, 14 day & 0.79 & 0.035 & -0.019 \\
6 & FRP: $5 \mathrm{~mm}, 7$ day & 0.78 & 0.039 & -0.023 \\
7 & FRP: 0 mm, 14 day & 0.78 & 0.014 & 0.011 \\
8 & FRP: $0.5 \mathrm{~mm}, 7$ day & 0.77 & 0.010 & 0.005 \\
9 & FRP: $5 \mathrm{~mm}, 3$ day & 0.77 & 0.042 & -0.025 \\
10 & FRP: $0.5 \mathrm{~mm}, 14$ day & 0.77 & 0.012 & 0.008 \\
11 & FRP: $0.5 \mathrm{~mm}, 3$ day & 0.77 & 0.009 & 0.003 \\
12 & FRP: $5 \mathrm{~mm}, 0$ day & 0.77 & 0.044 & -0.027 \\
13 & FRP: $0.5 \mathrm{~mm}, 0$ day & 0.76 & 0.009 & 0.001 \\
\hline & & & & \\
\hline
\end{tabular}




\section{Soiling Loss from Environmental Parameters}

The study by Micheli et al. ${ }^{25}$ showed the possibility of estimating soiling using nearby data. But, in accordance with the conclusions of Gostein et al. ${ }^{18}$ as well, it also highlighted that the predictions tend to worsen if the data points employed for the estimation are located more than $50 \mathrm{~km}$ from the investigated site. This means that estimating soiling losses at a new PV site can still be challenging if no soiling or PV performance data are available within that distance. For this reason, the NREL team also investigated the correlations between soiling and environmental parameters. The initial results of this effort have been published by Micheli et al., ${ }^{24}$ where a method to accurately determine soiling from six soiling stations was presented. This method was then used by Micheli et al., ${ }^{26}$ where soiling data from 20 soiling stations installed in the United States were compared with 102 parameters describing the station's geometry, site characteristics, and local pollution and meteorology to identify priority variables to determine annualized sitespecific soiling losses as part of the Phase 1 Milestone. The analysis (Figure 3 ) showed that the $\mathrm{PM}_{10}$ and $\mathrm{PM}_{2.5}$ measurements (expressing the mass concentrations, in $1 \mathrm{~m}^{3}$ of air, of airborne particulate matter less than 10 microns and less than 2.5 microns in diameter) are highly predictive

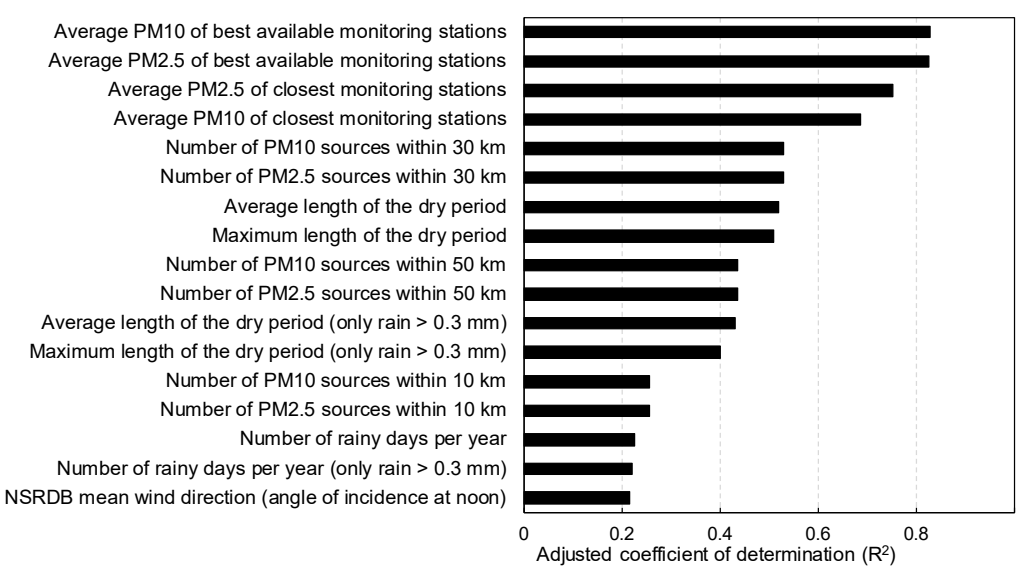

Figure 3. Parameters with the highest coefficients of determination and $p$-values $<0.05$ when related to the soiling ratio of the $\mathbf{2 0}$ soiling stations investigated in Micheli et al. ${ }^{26}$

of a site's soiling ratio, with

adjusted $\mathrm{R}^{2}$ up to 0.82 . Along with the pollution data, some rainfall parameters, describing the average and the maximum time between consecutive rainfalls, showed the strongest correlation with the soiling ratio. This analysis was later repeated with a larger number of data, using the measurements of 40 soiling stations installed in the United States. ${ }^{27}$ This new study aimed to extend results of the previous investigation by adding additional parameters to the number of variables considered previously and by analyzing how different resolutions, sources, or interpolation techniques can have an impact on predicting soiling. The investigation confirmed that particulate matter and rainfall statistics have the best correlations with soiling.

As shown in Figure 4, (where the significant variables describing the same parameter and sourced from the same database have been grouped for better readability), a normalized RMSE as low as $14 \%$ can be achieved by using the $\mathrm{PM}_{2.5}$ concentration measured at monitoring stations to estimate soiling. This value is already lower than the $25 \%$ normalized RMSE target for the Phase 3 milestone. The study showed how the correlation between $\mathrm{PM}_{2.5}, \mathrm{PM}_{10}$, and soiling ratio varied depending on the interpolation technique and on the distance between the soiling station and the Environmental Protection Agency (EPA) monitoring station. Overall, $\mathrm{PM}_{2.5}$ and $\mathrm{PM}_{10}$ were found to have similar performance for data extracted within $50 \mathrm{~km}$. $\mathrm{PM}_{2.5}$ performed consistently even if measured up to $250 \mathrm{~km}$ away from the soiling site, whereas prediction 
accuracy using $\mathrm{PM}_{10}$ dropped significantly at large distances. Among the investigated techniques, the distance-based interpolation techniques were found to be more robust at large distances. Among the rainfall data, the maximum and average length of the dry period showed the most significance, with the best results obtained if a minimum rainfall threshold of $1 \mathrm{~mm}$ or less (or even no threshold) was considered. The best overall results were obtained through a 2variable regression by combining the particulate matter and the maximum length of the dry period, yielding an $\mathrm{R}^{2}$ of 0.9 and a RMSE of $9 \%$, which meets the Phase 3 milestone.

Using PV system operational data presents numerous challenges. Systems can consist of many inverters as well as strings with different soiling rates. The output data are not consistent because some systems report power and some report current; not all report irradiance, which is needed to calculate the soiling ratio. Lastly, data quality can vary substantially from system to system. Systems can have inaccurate metadata information, tracking issues, clipping, temperature effects, gaps in reporting, and erroneous data, and data are shared in various formats from the utility managers.

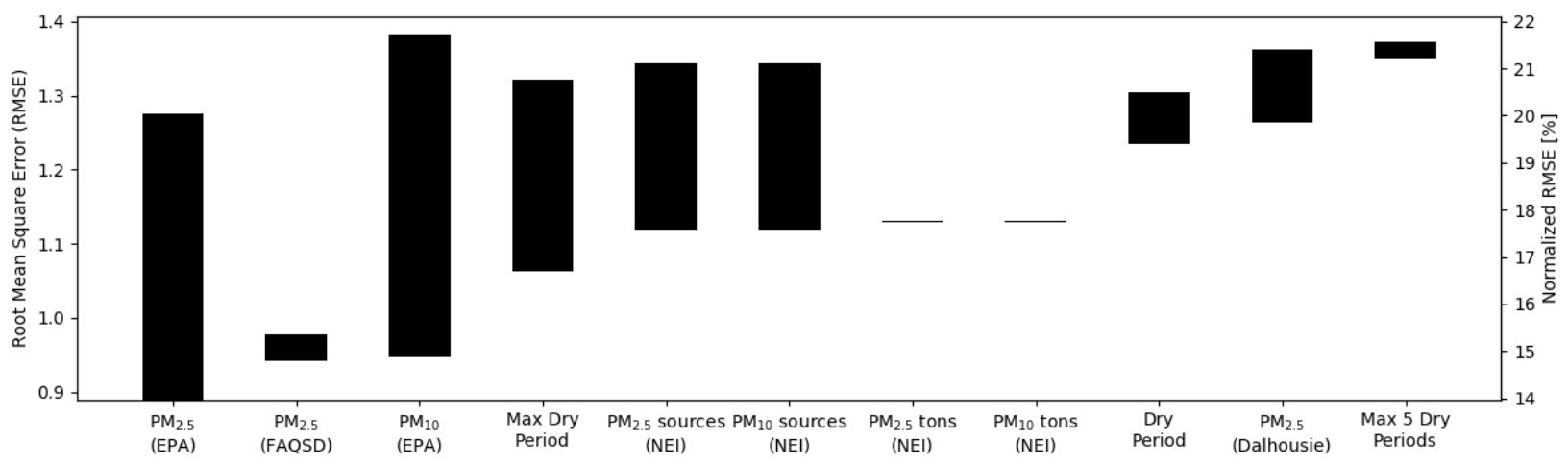

Figure 4. The root-mean-square errors and normalized root-mean-square errors obtained by comparing the actual soiling ratios with those predicted by using the significant linear correlations. ${ }^{27}$

Despite these challenges, working with system-derived soiling losses opens up the possibility of using 10-100x more locations with greater geographic diversity. To address these issues and to work with well-curated data from 100s or 1000s of sites, the data have to be organized and accessible. Therefore, a PostgreSQL database has been created to store the relevant time-series data and metadata for each system. An extract transform and load (ETL) procedure has been developed to store each PV performance dataset in a consistent way in the database and to univocally link it to a methodically organized metadata repository.

A new integrated soiling model has been built from the soiling extraction algorithm presented by Deceglie et al. ${ }^{2,19}$ to automatically pull data from the new database and to analyze them leveraging other PV resources, such as RdTools, National Solar Radiation Database (NSRDB), and PVLIB. Coincident meteorological data are extracted from NREL's NSRDB ${ }^{28}$ and added to the performance data to enable filtering and calculating the plane-of-array irradiance by using the functions available in the PVLIB package. Data are filtered to remove low irradiance and clipped data by using the RdTools package, and they are corrected according to referenced temperature and spectral models. ${ }^{29}$ The soiling ratios, calculated using NREL's PV soiling Python package, ${ }^{2,19}$ as well as the settings used in the calculation are stored in the database for analysis. 
This new infrastructure enables us to consistently extract soiling loss from a large number of sites and will be shared with other NREL projects. Using this infrastructure and building on the success of predicting soiling losses within the dataset of 41 soiling stations, we applied generalized linear models to soiling losses extracted from 336 different PV systems. With these models, we have achieved a relative RMSE of $14.2 \%$ with a 50/50 split of training and testing data per the Phase 3 milestone. Using an 80/20 split, we were able to achieve a relative RMSE of $14.6 \%$ using a model that includes interactions between variables. This is an encouraging result because interactions will likely to be important features as we work with more sophisticated models in the future. The details of the models, along with maps generated with them, will be the subject of a publication in follow-on work under a different project in FY19.

\section{Soiling Mechanisms}

To better understand and quantify soiling on solar panels, we investigated the adhesion mechanisms between dust particles and solar glass. The adhesion was determined using techniques such as quartz-crystal microbalances (QCMs) and force vs distance (F-z) measurements performed with an atomic force microscope (AFM). By monitoring the QCM frequency change, NREL was also able to define and detect when dust transitioned from loose particles to "cemented" on the glass surface. The AFM was able to directly measure the adhesion of simulated and actual dust particles as a function of surface roughness, humidity, and surface composition/energy. Furthermore, NREL quantified that the high voltages in the PV arrays induce additional particle attraction to the PV surface, additional adhesion on the surface, and ultimately increased soiling loss in the field.

\section{Initial Soiling Adhesion}

To emulate dust interacting with the front surface of a solar panel, we measured how oxidized AFM tips, $\mathrm{SiO}_{2}$ glass spheres, and actual dust particles adhered to PV glass. The van der Waals forces were evaluated by measurements performed with zero relative humidity $(\mathrm{RH})$ in a glovebox, and capillary forces were measured in a stable environment created inside the AFM enclosure with RH values ranging from $18 \%$ to $80 \%$. To simulate topographic features of the solar panels caused by factors such as cleaning and abrasion, we induced different degrees of surface roughness in the solar glass. We were able to 1) identify and quantify both the van der Waals and capillary forces, 2) establish the effects of surface roughness, $\mathrm{RH}$, and particle size on the adhesion mechanisms, and 3) compare adhesion forces between well-controlled particles (AFM tips and glass spheres) and actual dust particles.

At lower RH values, adhesion is dominated by van der Waals forces, and at higher RH, capillary forces can dominate if the water layer is thick enough to overcome the surface asperity.

However, surface roughness has a major effect on the adhesion process by reducing contact area due to surface topographic features; thus, the value of both forces substantially decreases as roughness increases. So, for AFM probes, which have a low aspect ratio and can penetrate the surface topographic features, the adhesion forces were not substantially affected by surface roughness. The main difference between the adhesion of AFM tips and glass spheres-compared to actual dust particles - is that the topographic features of the dust particles substantially impact the contact area such that adhesion due to short-range van der Waals or capillary forces does not significantly depend on particle size (Figure 5). These results resolve the field observations that larger dust particles can be blown off by wind, but smaller dust particles cannot. With smooth 
particles, the contact area effectively increases with particle diameter; thus, the adhesion force increases as the shear force from wind increases, suggesting that the larger particles should adhere as well as smaller particles. However, because of the random nature of the particle roughness - and consequently, the adhesion/contact area of actual dust particles - the adhesion cannot be related to dust particle size. Thus, the increase in wind force with particle size increases, and, on average, larger particles will be more susceptible to be removed by wind when only van der Waals and capillary forces are in effect. ${ }^{30}$

Similar experiments were performed on the surface of different materials and PV glass with different coatings (e.g., Teflon, ultraviolet-treated Si, three different commercial coatings, and different inhouse coatings). The key difference among these different coatings/materials is the wide range of "surface energy" as measured by water contact angle. The water contact angles ranged from near zero (i.e., high surface energy, very hydrophilic) to more than $120^{\circ}$ (i.e., low surface energy, very hydrophobic). Systematic evaluation of the F-z measurements using 20- $\mu$ m-diameter $\mathrm{SiO}_{2}$ spheres at different RH $(\sim 20 \%-80 \%)$ showed little direct correlation between the surface energy of the different coatings and the adhesion force. ${ }^{31}$ As with the PV glass, the magnitude of the initial adhesion force was dominated by the surface roughness. These results may help explain field observations where both superhydrophobic and superhydrophilic surfaces appear to reduce soiling rates. This may be related to the fact that these types of coatings typically rely on "surface texture" (i.e., rough surfaces) to achieve the "super"-

hydrophobic/hydrophilic properties.

\section{Electric-Field-Induced Soiling (Particle Attraction and Adhesion)}

The standard practice of arraying modules together to operate at high voltages - and thus, to reduce resistive losses - has been demonstrated to have unanticipated consequences. The most wellknown of these is potential-induced degradation (PID), where the high voltages cause sodium migration from the glass to the cells and result in power loss. Recently, NREL has been investigating the impact of these high voltages (modules being at up to $1500 \mathrm{~V}$ ) on soiling. These investigations were initiated because the electric fields from the high voltages extend well outside the module, thus having the possibility of attracting dust particles and holding them more strongly to the glass surface. To measure the forces, real dust particles and silica spheres (with well-defined shape and chemical compositions) were attached to AFM cantilevers and F-z) curves were measured using a piece of crystalline-Si module with a deposited metal strip on the 
front glass surface to emulate a module frame. The electric field force (Fes) and van der Waals force (Fvw) can be well separated from the F-z curve (Figure 6a) due to the long interaction ranges of Fes ( $\mu \mathrm{m}$ to sub-mm depending the voltage, Vs) and the short range of Fvw $(\sim \mathrm{nm})$.
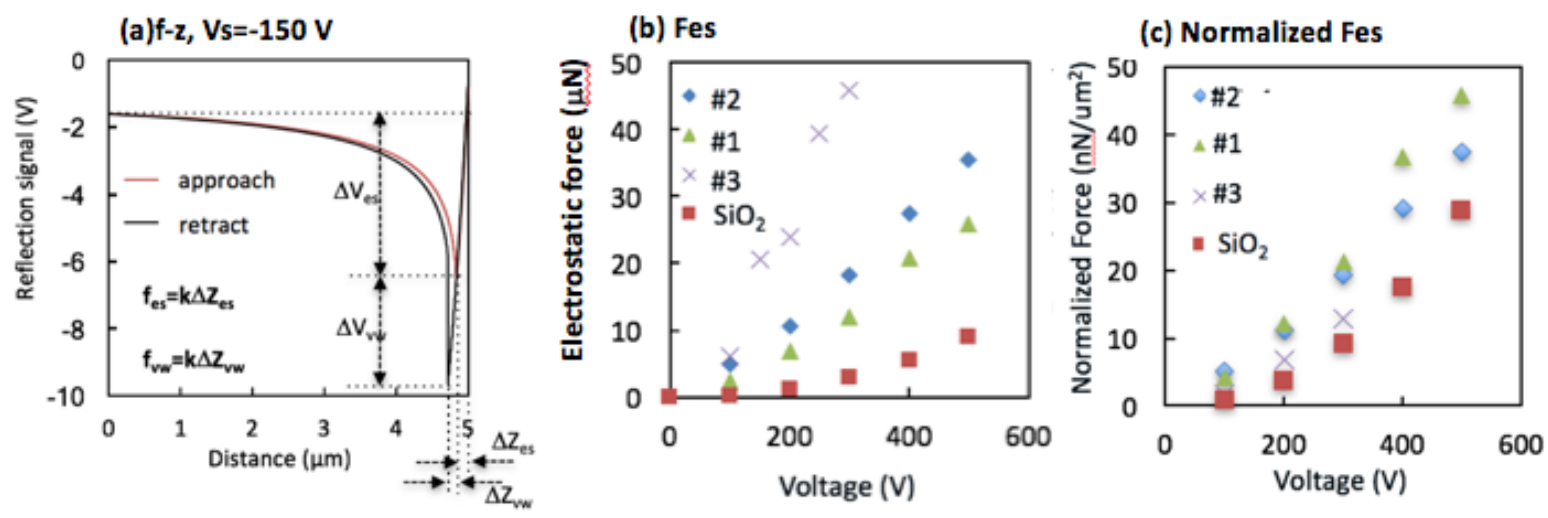

Figure 6. (a) AFM F-z curve at Vs $=-150 \mathrm{~V}$, (b) Fes measured on three dust particles with different sizes and shapes and on a silica sphere with diameter of $20 \mu \mathrm{m}$, (c) normalized Fes per unit area facing to the glass. 
Fes was measured as a functions of: 1) Vs applied to the cell, 2) vertical distance above the module glass surface, 3) dust particle volume and shape, 4) lateral position away from grounding frame, and 5) time after tuning off Vs for simulating the remaining Fes after sunset. The results elucidate the following: 1) Fes on typical dust particles dominates the adhesion force of $\sim 2.5 \mu \mathrm{N}$ with just Vs $=100 \mathrm{~V}$ (e.g., single large module voltage not in an array), which is several times the Fvw $(\sim 0.5 \mu \mathrm{N})$ and capillary force $(\mathrm{Fcp} \sim 1 \mu \mathrm{N}) .{ }^{31} \mathrm{Fes}$ increases rapidly with Vs (Figure $6 \mathrm{~b}$ ) by about one order of magnitude larger (tens of $\mu \mathrm{N})$ with $\mathrm{Vs}=500 \mathrm{~V}$ (e.g., average module voltage in a 1000-V array). 2) Fes decreases the farther away from the glass surface, but the amount of Fes depends on the Vs and particle size. For a $20-\mu \mathrm{m}$ silica sphere, the attraction force extended over $200 \mu \mathrm{m}$ at $\mathrm{Vs}=1000 \mathrm{~V}, 50 \mu \mathrm{m}$ at $\mathrm{Vs}=500 \mathrm{~V}$, and $10 \mu \mathrm{m}$ at $\mathrm{Vs}=100 \mathrm{~V}$. These Fes interaction distances are many orders of magnitude longer than Fvw and Fcp $(\sim \mathrm{nm})$, and thus, substantially extend the typical two-dimensional adhesion forces of Fvw and Fcp to longrange three-dimensional attraction forces. 3) The magnitude of Fes depends on the dust particle materials and topology (Figure 6b). Specifically, charged particles, more polarizable materials, and particles with larger cross-sectional areas facing the glass (e.g., mica or flatter dust) (Figure 6c) will be more attracted and adhered. 4) Moving from the center of the glass to the "grounded frame," Fes begins to decrease about $5 \mathrm{~mm}$ from the frame and is zero at the frame, where the grounding prevents the electric fields from extending beyond the glass surface. However, in the region close to the grounded frame, as observed with PID, the leakage current is greatest. 5) Due to semi-permanent induced dipole formation in the glass and particle, as well as static electrical charge build-up on the module glass surface, Fes may remain (decaying from several $\mu \mathrm{N}$ ) for several hours after switching off Vs, indicating that the dust attraction and adhesion will be enhanced long after the sun has set. The static electric component may be quickly reduced if there is a path to ground for the inverter electronics and modules.

Finally, a set of experiments were performed where three PV modules were placed side by side at a site in Riverside, CA. One panel was biased at $+1000 \mathrm{~V}$, another at $-1000 \mathrm{~V}$, and the third operated normally. As shown in Figure 7, the panels biased at $\pm 1000 \mathrm{~V}$ both showed a substantial decrease in power loss compared to the unbiased panel. This definitively demonstrates that under the appropriate environmental conditions, soiling losses may be substantially higher in PV arrays that operate at elevated voltages (e.g., $\pm 1000 \mathrm{~V}$ to $\pm 1500 \mathrm{~V}$ ).

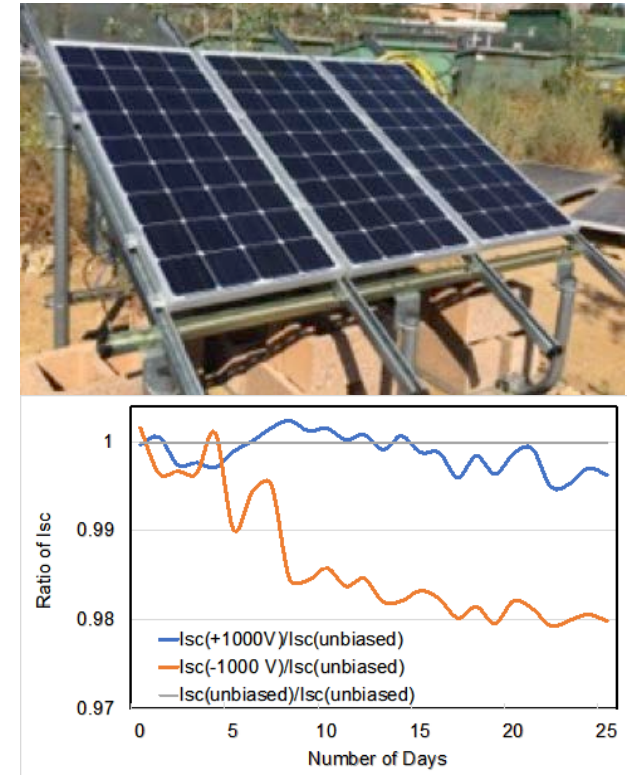

Figure 7. Image (above) and soiling loss comparison data (below) of PV modules in Riverside, CA. One module operated with no bias, whereas the other two were biased at $+1000 \mathrm{~V}$ and $-1000 \mathrm{~V}$. The ratio of the measured short-circuit currents are shown and indicate that the $-1000 \mathrm{~V}$ module is soiling faster than the $+1000 \mathrm{~V}$ module, which is soiling faster than the unbiased module.

\section{Cementation}

Part of the immense difficulty in understanding soiling are the complex processes involved in "loose" dust particles becoming more strongly adhered to the PV module surface due to a variety 
of processes. To quantify these processes, NREL adopted the industry definition and properties of "cementation" as basically being a process where loose particles transform to fixed particles that can transmit shear waves. Thus, NREL was able to use a QCM (see Figure 8) that accurately measures small changes in vibration to measure the actual onset and adhesion of cementation processes. ${ }^{32}$ The key here is that a QCM is relatively inexpensive and yet uniquely capable of measuring the onset of the shear-wave formation that, by definition, marks the "phase or percolation transition" from individual particles into mechanically monolithic solids

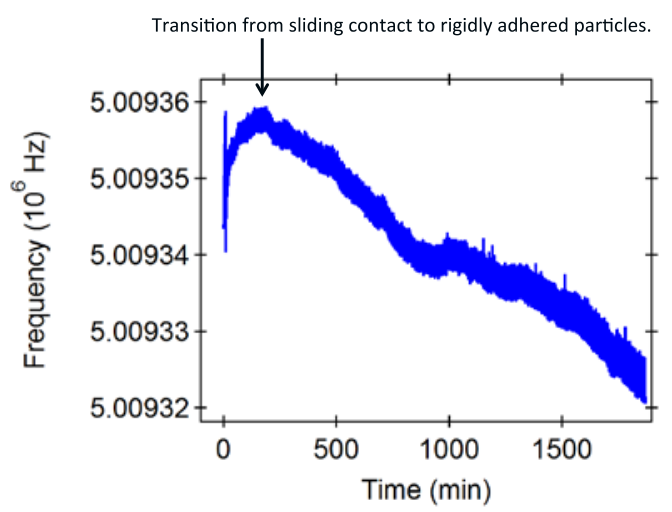

Figure 8. QCM data demonstrating the onset of cementation of halite dust particles during cycling between dry and humid air. able to transmit shear forces. The main issue involves interpreting the frequency changes related to larger particles (i.e., greater than $40 \mu \mathrm{m}$ ) on the surface of the QCM that are typical of soiling. Because of the large size, the particles cannot oscillate with the QCM, but are inertially clamped to the QCM crystal surface and thus apply a restoring force. This force may change over time due to friction-induced wear. However, as seen in Figure 8, the onset of cementation is clearly measured by the QCM, when the individual sliding particles become rigidly adhered. Additional work will be performed to quantify the adhesion strength and determine the exact adhesion mechanisms involved.

Thus, we use the term cementation to describe particles that have adhered to surfaces or to each other such that they resist removal by shear forces applied by wind, water, gravity, brushing, or other means. As reported by D'Amour and coworkers, shear stiffness observed in this type of measurement system is a "faithful indicator of interparticle cohesion." 33 Our work with this measurement system is further motivated by other factors: virtually all module cleaning processes are based on the application of shear forces. In addition, a recent review on module soiling points out that resuspension of soil from modules is controlled mainly via shear forces resulting from hydrodynamic drag. ${ }^{34}$

The key findings from these investigations found that humidity was a key factor in almost all cementation processes. Even highly cementing materials, such as the clay palygorskite, did not cement until the humid air was introduced into the system. Although palygorskite cements with only a minimal amount of water, other minerals required tens to hundreds of cycles between dry and humid air before cementation occurred (e.g., calcite and gypsum), whereas some materials (e.g., silica) did not cement at all in our tests. Based on reports in the literature, a number of minerals commonly found in soiling deposits ${ }^{35,36}$ were purchased as sized, pure materials, then screened for their propensity to undergo the cementation phase transition. In addition to the minerals described in the literature, the cementation and adhesion of cellulose was studied on the basis of it being a proxy for pollen and other plant material. These types of materials appear to cement quickly. We hypothesize that the clay particles, which are typically sheet-like, have a higher ratio of surface area to mass than the calcite particles, and thus, they are more prone to sticking to the oscillator. This, by itself, is a significant finding: quartz-crystal resonators of the sort used here appear to be exquisitely sensitive to the mechanical properties of dust layers, and 
their use could ultimately lead to improved methods in artificial soiling, soil adhesion testing, module cleaning, and other areas of interest to the PV soiling community.

\section{Soiling Standards}

The literature is concerned with the soiling of $\mathrm{PV}^{37}$ and concentrating solar power (CSP), ${ }^{38,39}$ and typically provides a basic correlation with the loss of optical transmittance and the degradation mode(s). In other cases, artificial abrasion methods are performed ${ }^{40}$ without the critical correlation to damage from natural weathering. Historically, many groups have developed anti-reflection/anti-soiling (AR/AS) coatings, but we lack an understanding of the efficacy of AR and AS coating types (including hydrophilic and hydrophobic) relative to the cleaning methods used in the PV industry. Lastly, the understanding of natural soiling and its effects is not complete and would benefit from additional study. Thus, at the outset of this project, NREL developed a plan to simultaneously obtain field data and to develop laboratory tests that can emulate the damage/degradation observed in the field. Ultimately, this work is focused on providing the critical feedback needed for developing a PV module abrasion test standard, but was designed to also advance the understanding of soiling issues, in general.

\section{Evidence from Field Samples and Veteran Modules}

Details and initial results of the field study are described in Toth et al. ${ }^{41}$ and Einhorn et al. ${ }^{42}$ The tests included deploying replicate coupon specimens for 10 "materials" consisting of coated or uncoated substrates, $75 \mathrm{~mm} \times 75 \mathrm{~mm} \times 3.2 \mathrm{~mm}$ in size. The coatings in the studied had AR and/or AS functionalities. The specimens were weathered in or near the soiling-prone cities of Tempe, Arizona; Sacramento, California; Mumbai, India; Kuwait City, Kuwait; and Dubai, United Arab Emirates. Separate racks of samples at each site were either: not cleaned (NC); cleaned with a hog-bristle dry brush (DB); cleaned with a low-pressure water spray (WS); or cleaned with a wet polypropylene sponge and rubber squeegee (WSS) (Figure 9). Except for Kuwait, where the samples were cleaned daily, at all the other sites the samples were cleaned once per month. The specimen racks were assembled and fielded in 2016, with the initial sets of samples being returned after the first year in 2017, and the second sets of samples being returned after the second year in 2018. For transport back to NREL for evaluation, the samples were encased with a specially designed cover rail to protect the samples during shipping and handling. 
To date, 18 veteran modules have also been collected and examined for reference relative to the field study. The presence of biological contamination was confirmed for several of the modules. Changes in surface chemistry of the glass with natural aging (including the accumulation of iron and aluminum) were quantified for some of the modules. It was not possible to extract samples from the veteran modules for optical transmission characterization for several reasons, including the limited specimen size that can be obtained from tempered glass as well as the difficulty in completely removing the encapsulant from the glass surface on the interior of the module. The exterior glass surface morphology, however, was examined for future reference for the abrasion standard.

Biological contamination is a well-known issue on building facades. ${ }^{43}$ But due to the much higher PV temperatures, it was not originally anticipated; however, it was a substantial issue on both the glass specimens and veteran modules from several locations. The Alternaria genus of ascomycetous fungi was identified from NREL specimens. Fungi were confirmed to interact with inorganic contamination, increasing their effect on optical performance and resulting in greater loss of power production in PV installations.

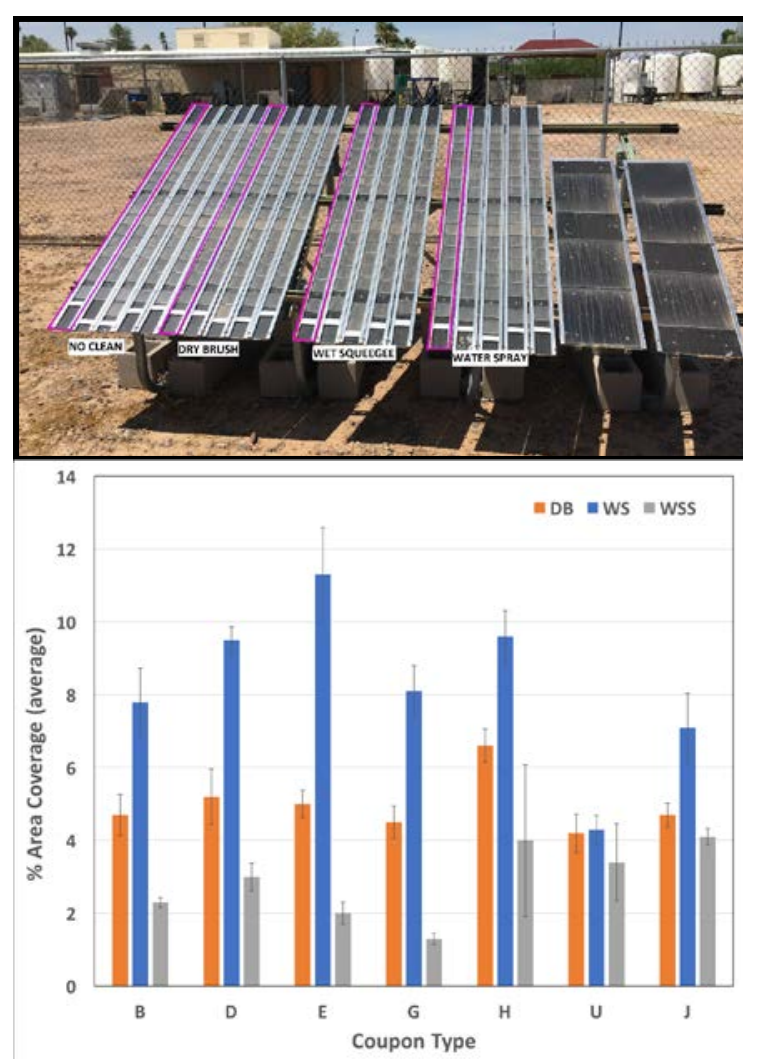

Figure 9. Image of field samples (top) and graph of data (bottom) showing the percent area coverage (PAC) of field-aged glass coupons from Dubai as a function of coating and cleaning technique $(D B=$ dry brush, WS = water spray, and WSS = wet sponge and squeegee). The PAC of each coupon is calculated as the average of the PAC of five locations on the same coupon.

Analysis of the initial returned field coupons

focused on quantifying contamination to assess the efficacy of cleaning and the effectiveness of the coating materials (Figure 9). From that, the DB cleaning method was found to induce more damage (in the presence of contamination) than the cleaning methods that used water (WS and WSS). Furthermore, the WSS method appeared to provide the best cleaning of the coupon surfaces and to decrease the development of fungus colonies on coupon surface. Methods including spectrophotometry (with optical analysis) and electron microscopy were used to verify the integrity of coating materials (or their damage/removal from the cleaning methods). For example, optical microscopy analysis was used to quantify the amount of area coverage due to fungi and that due to more typical soiling from dust. As shown is Figure 10, for both the dust and fungi, there is a direct linear correlation between surface area coverage and decrease in solarweighted transmittance and thus PV power loss due to soiling. However, correlations between coating properties and soiling are very difficult to quantify, and substantially more work in this area is required. Ultimately, we hope that examination of the coupon specimens will help in selecting coating materials, cleaning methods, and locations to focus on as the abrasion standard is developed. 


\section{Accelerated Tests and IEC Standard}

Review within the International Photovoltaic Quality Assurance Task Force (PVQAT) Task Group 12-3 (TG 12-3, soiling and coatings) identified that abrasion of AR and AS coatings was the foremost concern in the PV industry, not delamination of AR/AS coatings. Three types of accelerated tests are commonly used for research and development, material selection, and the design qualification of coatings: falling sand; ${ }^{44}$ forced sand impingement; $;{ }^{45}$ and machine abrasion. ${ }^{46}$ Although existing standardized methods used in other industries might have applicable components, none are correlated or tailored to PV. For example, the use of the falling sand test with common silica particulate abrasives was found in TG12-3 to frost glass. This is too severe and not observed with veteran PV modules from the field. Thus, the present sand drop test needs to be adjusted to provide useful information for PV coatings that are typically more susceptible to damage compared to the glass. Therefore, developing a test standard covering abrasion methods was initiated to respond to the industry interest identified in TG12-3.

A literature review of abrasion test standards, including those cited in the PV industry as well as methods from other industries, resulted in an NREL report. ${ }^{47}$ After the report, the recent development of abrasion test methods for the automobile industry emerged as a guiding example - where the damage morphology from field study was used to select the relevant test methods and guide their development for polymer/other glazings ${ }^{48}$ In addition, based on PVQAT TG12-3 feedback, it appears that cleaning of soiled modules is more damaging than natural abrasion, e.g., blowing sand. Thus, issues with the cleaning equipment are being explored, where the PV industry frequently leverages the equipment and methods used in the building glazing industry, e.g., water-fed pole brushes.

Research activities were conducted to verify some of the descriptions and conclusions from TG12-3 as well as gain familiarity with the artificial abrasion methods. First, the falling sand test was performed using standardized sand from the cement industry. ${ }^{49}$ The ASTM method ${ }^{50}$ was confirmed to frost (abrade) glass, giving a heterogeneous wear pattern. Much of the subsequent experimental work then focused on machine abrasion using a linear reciprocating brush, with both wet slurry and dry abrasive. The brush tests, both for A4 (coarse) "Arizona" (AZ) test dust,${ }^{51}$ confirmed that the slurry abrasive is less damaging (i.e., difficult to quantify changes in transmittance) than dry abrasive used with the same brush. Comparison of the three mostcommon bristle materials used in the industry (nylon, polyester, and hog bristle) confirmed that 
nylon was the most damaging and also may result in the deposition of a contamination film when A4 test dust was used.

A test standard (IEC 62788-7-3 provisioned) was initiated in the IEC Working Group 2 (WG2, PV modules) in January 2018. The scope of the standard includes falling sand, forced sand impingement, ${ }^{52}$ and machine abrasion methods. Both linear and rotary brush methods were proposed, based on the popular use of robots for cleaning in the PV industry. Recent interest in the erosion of backsheet materials found WG2 requesting that the use of the methods for backsheet materials also be specified in the abrasion standard. Recent development of the standard focused on building consensus for details of the methods, including the abrasive (i.e., now A3 "medium" AZ dust) and the bristle materials.

\section{Artificial Soiling}

An indoor in-situ soil deposition method was developed by partners at Arizona State University to simulate natural soil deposition on glass coupons or multi-cell PV modules. This method controls variable ambient humidity, module temperature, and dust composition within a single enclosure to create a natural and uniform soil deposition layer. Various electrical and optical characterizations were used to quantify technique repeatability, and the dust uniformity and the effect of the deposited soiling on glass coupons or multi-cell PV modules. This included image processing to determine the particle size of deposited soiling and module current-voltage measurements to demonstrate that soiling loss is similar to that of field modules. Ultimately, this work is leading to the development of an international standard to help quantify the efficacy and reliability of PV module coatings (e.g., AR or AS).

\section{Conclusions}

As outlined in the Executive Summary and throughout this document, this project had many substantive accomplishments too numerous to document here. However, the major results include:

- Being able to measure soiling losses directly from production data and accurately predicting soiling losses at new sites.

- Understanding the major mechanisms associated with initial adhesion and cementation, and finding that high voltages and humid environments increase soiling losses (the latter due to fungi growth).

- Establishing road maps and a scientific basis to develop PV module coating abrasion and testing standards.

- Completing all milestones and progress indicators on time and at or beyond the specified requirements.

Ultimately, these accomplishments will help the PV community to measure soiling loss, more accurately predict the impact of soiling on production output, develop better AR and AS coatings, better optimize cleaning schedules and techniques, and ultimately, have standards for testing PV coatings and cleaning methodologies. All these benefits will reduce uncertain, reduce finance cost, increase energy production, and thus, reduce LCOE. 


\section{Budget and Schedule}

Overall, this project was well funded by the U.S Department of Energy (DOE) and allowed NREL to have substantive accomplishments in many areas to help the industry in PV module soiling, starting in October of 2015. However, most of these accomplishments would not have been possible without the incalculable "cost share" of knowledge, capabilities, resources, and especially production/soiling station data provided by our partners. Ultimately, our partners provided twice to more than 10 times the help/data than was initially proposed in the initial technical work plan to help us develop soiling loss procedures from production data and soiling loss models from environmental parameters, as well as providing coated glass and sites for the coupon testing. Thus, the overall cost share from our partners to this project was several times the amount DOE provided. The project efficiently utilized all of the DOE funding provided and met all milestones and progress indicators on time. Thus, no substantial deviation in spending or schedule occurred. The project is in the process of wrapping up and transitioning some activities to new DOE-funded projects that will work over the next few years to build on the achievements of this project.

\section{Path Forward}

While this project was very successful, there are several areas that can build on the accomplishments and/or new paths to follow. In terms of soiling loss measurements and predictions, future studies need to develop a better understanding of spatial and temporal nonuniformity of soiling at the module, array, and site level as well as for regions between sites. The accumulation of soiling, indeed, can be strongly seasonal, ${ }^{17,24}$ subject to interannual variations, ${ }^{19}$ and nonuniformly distributed over a PV site. Some of these issues will be investigated in a new DOE project at NREL focused on module degradation. In this work, the soiling map and some of the predictive modeling will be formalized and added to RdTools.

The use of soiling stations should not be disregarded because they can be a useful tool to investigate the nonuniformity of soiling over plants or even strings of modules and to enhance the soiling extraction models by developing methods to automatically distinguish soiling from other reliability issues. In this light, two U.S. provisional patent applications were filed on April 5, 2018 and June 26, 2018 at the United States Patent \& Trademark Office (Application numbers No. 62/652,955 and 62/690,086). The applications, based on the NREL Record of Invention No. 17-85, present the design and the validation of a new cleaning-less soiling station. The invention uses a transmittance measurement to quantify the soiling accumulated on a PV glass mounted parallel to the PV modules under investigation. The invention does not require cleanings to be performed and, as described by Micheli et al., ${ }^{53}$ it can be used to determine the losses of various PV technologies. Made of standard low-cost components, the product developed from the invention is expected to have a price lower than standard automated soiling stations and be competitive with other cleaning-less soiling detectors recently launched in the market. In addition, the absence of moving parts will make it less exposed to reliability issues and the use of transmittance measurements will lead to a better signal-to-noise ratio than devices based on reflectance measurements.

Perhaps the most difficult work attempted in the project was to understand the mechanisms and processes involved with soiling and adhesion to the PV module surface. As discussed above, we 
made substantial headway in this area, but more work is needed to identify the chemical processes involved so that effective mitigation can be developed. For example, cementation appears to involve water and certain minerals, but much more work is needed to determine if adjusting the surface chemistry of the module can reduce cementation formation. Similarly, it is clear that initial dust deposits on the module surface are not significantly affected by the surface composition. However, initial dust adhesion is well correlated to surface roughness, which may also play a substantive role in cementation. Finally, the extent of fungi growth and its impact on PV production needs to be quantified; if this turns out to be a substantial problem, then adequate mitigation practices need to be developed and implemented.

The standards work will continue as part of the NREL PVQAT core effort. This will include continued field sample evaluations and developing testing protocols for standards. Ultimately, standards for coating abrasion, artificial soiling/coating efficacy, and PV cleaning will be developed.

\section{Publications Resulting from This Work}

\section{Peer-reviewed journal papers}

A. Einhorn, L. Micheli, D. Miller, L.J. Simpson, H.R. Moutinho, B. To, C.L. Lanaghan, M. Muller, S. Toth, J.J. John, S. Warade, A. Kottantharayl, and C. Engtrakul, "Evaluation of Soiling and Potential Mitigation Approaches on Photovoltaic Glass," IEEE J. Photovoltaics 9(1), 233239, November 2018.

L. Micheli and M. Muller, "An investigation of the key parameters for predicting PV soiling losses,” Prog. Photovoltaics Res. Appl., 25(4), 291-307, Apr. 2017.

M.G. Deceglie, L. Micheli, and M. Muller, "Quantifying Soiling Loss Directly from PV Yield," IEEE J. Photovoltaics, 8(2), 547-551, March 2018.

L. Micheli , M.G. Deceglie, and M. Muller, "Mapping Photovoltaic Soiling Using Spatial Interpolation Techniques,” IEEE J. Photovoltaics, (accepted) 2018.

L. Micheli , M.G. Deceglie, and M. Muller, "Predicting photovoltaic soiling losses using environmental parameters: An update,” Prog. Photovoltaics Res. Appl., (accepted) 2018.

C.-S. Jiang, H.R. Moutinho, B. To, C. Xiao, C. Perkins, M. Muller, M.M. Al-Jassim, and L.J. Simpson, "Strong Electric Field Attraction and Adhesion Forces of Dust Particles on Photovoltaic Modules," Journal of Photovoltaics, (accepted) 2018.

L. Micheli, E.F. Fernandez, J.A. Caballero, G.P. Smestad, G. Nofuentes, T.K. Mallick, and F. Almonacid, Correlating Photovoltaic Soiling Losses to Waveband and Single-Value Transmittance Measurements, Submitted to PiP in July 2018

S. Toth, M. Muller, D.C. Miller, H. Moutinho, B. To, L. Micheli, J. Linger, C. Engtrakul, A. Einhorn, and L. Simpson, "Soiling and cleaning: Initial observations from 5-year photovoltaic glass coating durability study," Sol. Energ. Mat. Sol. C, 185, 375-384, 2018. 
H.R. Moutinho, C.-S. Jiang, B. To, C. Perkins, M. Muller, M.M. Al-Jassim, and L. Simpson, "Adhesion Mechanisms on Solar Glass - Effects of Relative Humidity, Roughness, and Particle Shape and Size." Solar Energy Materials and Solar Cells, 172, 145, 2017.

IEC 62788-8-2 (Abrasion of PV surfaces), Work Item for international standard accepted and moving to next phase 2018 .

\section{Conference papers}

M.G. Deceglie, L. Micheli, and M. Muller, "Quantifying Year-to-Year Variations in Solar Panel Soiling from PV Energy-Production Data," in 2017 IEEE 44th Photovoltaic Specialist Conference (PVSC), 2017.

M. Muller, L. Micheli, and A. A. Martinez-Morales, "A Method to Extract Soiling Loss Data from Soiling Stations with Imperfect Cleaning Schedules," in 2017 IEEE 44th Photovoltaic Specialist Conference (PVSC), 2017.

L. Micheli, D. Ruth, and M. Muller, "Seasonal Trends of Soiling on Photovoltaic Systems," in 2017 IEEE 44th Photovoltaic Specialist Conference (PVSC), 2017.

M. Gostein, K. Passow, M.G. Deceglie, L. Micheli, and B. Stueve, "Local Variability in PV Soiling Rate," in 7th World Conference on Photovoltaic Energy Conversion (WCPEC-7), 2018.

C.-S. Jiang, H.R. Moutinho, B. To, C. Xiao, C. Perkins, M. Muller, M.M. Al-Jassim, and L.J. Simpson, "Strong Electric Field Attraction and Adhesion Forces of Dust Particles on Photovoltaic Modules," Proceedings 2018 WCPEC-7.

A. Einhorn, L. Micheli, D. Miller, L.J. Simpson, M. Muller, S. Toth, J.J. John, A. Kottantharayl, and C. Engtrakul, "Optical Microscopy Study of Soiling on PV Glass: Evaluation of Possible Mitigation Strategies," Proceedings 2018 WCPEC-7.

H. Moutinho, B. To, C.-S. Jiang, C. Engtrakul, A. Einhorn, A. Selling, H. Yemam, M. Al-Jassim, and L. Simpson, "Effects of Solar-Glass Coatings on the Adhesion Forces Related to Soiling," Proceedings 2018 WCPEC-7.

P. Ravi, M. Muller, L. Simpson, D. Choudhary, S. Mantha, S.G. Subramanian, S. Virkar, T. Curtis, and G. Tamizhmani, "Indoor In-Situ Soil Deposition Chamber: Validation of AntiSoiling Coating Claims." Proceedings 2018 WCPEC-7.

L.J. Simpson, C. Weston, P. Ndione, B. McDanold, S. Toth, C.S. Jiang, M. Muller, H. Mountinho, D. Miller, L. Micheli, G. Perrin, R. Huntamer, and A. Martinez-Morales, "Electric Field Induced Soiling of PV Modules." Proceedings 2018 WCPEC-7.

L. Micheli, M.G. Deceglie, and M. Muller, "Mapping Photovoltaic Soiling Using Spatial Interpolation Techniques.” Proceedings 2018 WCPEC-7.

M. Gostein, K. Passow, M.G. Deceglie, L. Micheli, and B. Stueve, "Local Variability in PV Soiling Rate.” Proceedings 2018 WCPEC-7. 
L. Micheli, M. Deceglie, and M. Muller "On seasonal soiling trends and their predictability," Conference Proceeding PVSC 2017.

M. Muller, L. Micheli, and A. Martinez-Morales, "A Method to Extract Soiling Loss Data from Soiling Stations with Imperfect Cleaning Schedules.” Conference Proceeding PVSC 2017.

M. Deceglie, L. Micheli, and M. Muller, "Quantifying Year-to-Year Variations in Solar Panel Soiling from PV Energy-Production Data.” Conference Proceeding PVSC 2017.

L. Micheli et al., "A unified global investigation on the spectral effects of soiling losses of PV glass substrates: preliminary results." Conference Proceeding PVSC 2017.

C.L. Perkins, M. Muller, and L. Simpson, "Laboratory Studies of Particle Cementation and PV module Soiling." Conference Proceeding PVSC 2017.

L.J. Simpson, et al., "NREL Efforts to Address Soiling on PV Modules." Conference Proceeding PVSC 2017.

H.R. Moutinho, C.-S. Jiang, B. To, C. Perkins, M. Muller, M.M. Al-Jassim, and L. Simpson, "Investigation of Adhesion Forces Between Dust Particles and Solar Glass." Conference Proceeding PVSC 2017.

M.G. Deceglie, M. Muller, Z. Defreitas, and S. Kurtz, “A Scalable Method for Extracting Soiling Rates from PV Production Data," in 2016 IEEE 43rd Photovoltaic Specialist Conference (PVSC), 2016.

L. Micheli, M. Muller, and S. Kurtz, "Determining the effects of environment and atmospheric parameters on PV field performance," in 2016 IEEE 43rd Photovoltaic Specialist Conference (PVSC), 2016, 1724-1729.

\section{Reports and other resources}

U.S. provisional patent application filed on April 5, 2018 at the United States Patent \& Trademark Office (Application No. 62/652,955), corresponding to NREL Record of Invention PROV/17-85. Title: "Soiling spectral deposition detector," Inventors: E.F. Fernandez, M. Muller, L. Micheli, F. Almonacid.

U.S. provisional patent application filed on June 26, 2018 at the United States Patent \& Trademark Office (Application No. 62/690,086), corresponding to NREL Record of Invention PROV/17-85A. Title: "Methods and Systems for Determining Soiling on Various Photovoltaic Devices.” Inventors: E.F. Fernandez, M. Muller, L. Micheli, F. Almonacid.

L. Micheli, D. Ruth, M.G. Deceglie, and M. Muller, "Time Series Analysis of Photovoltaic Soiling Station Data: Version 1.0, August 2017," Golden, CO, 2017.

National Renewable Energy Laboratory, "Photovoltaic modules soiling map," 2018. [Online]. Available: https://www.nrel.gov/pv/soiling.html. 
National Renewable Energy Laboratory, "Code for extracting soiling loss from PV plant data," 2018. [Online]. Available: https://github.com/NREL/pv_soiling.

D.C. Miller, M.T. Muller, and L.J. Simpson, Review of Artificial Abrasion Test Methods for PV Module Technology, NREL/TP-5J00-66334, 2016, 1-25.

\section{Presentations}

L.J. Simpson, “Optical Microscopy Study of Soiling on PV Glass: Evaluation of Possible Mitigation Strategies." Presented at $20187^{\text {th }}$ World Conference on Photovoltaic Energy Conversion (WCPEC-7).

C.-S. Jiang, "Strong Electric Field Attraction and Adhesion Forces of Dust Particles on Photovoltaic Modules," Presented at 2018 WCPEC-7.

C.-S. Jiang, Effects of Solar-Glass Coatings on the Adhesion Forces Related to Soiling," Presented at 2018 WCPEC-7.

P. Ravi, "Indoor In-Situ Soil Deposition Chamber: Validation of Anti-Soiling Coating Claims." Presented at 2018 WCPEC-7.

L.J. Simpson, "Electric Field Induced Soiling of PV Modules.” Presented at 2018 WCPEC-7.

L. Micheli, M.G. Deceglie, and M. Muller, "Mapping Photovoltaic Soiling Using Spatial Interpolation Techniques." Presented at 2018 WCPEC-7.

M. Gostein, K. Passow, M.G. Deceglie, L. Micheli, and B. Stueve, "Local Variability in PV Soiling Rate." Presented at 2018 WCPEC-7.

G.P. Smestad, L. Micheli, T. Germer, and E.F. Fernandez, Optical Characterization of PV Glass Coupons and PV Modules Related to Soiling Losses, PVQAT TG12 Webinar Series, May 8th, 2018

L. Simpson et al., “Addressing Soiling from Interface Chemistry to Practicality,” DOE SETO Portfolio Review, Feb. 12-14, 2018, Washington DC.

L. Micheli and M. Deceglie, "Quantifying and Mapping PV Soiling a Scale,” 2018 PV Reliability Workshops, 2/27-3/1 Lakewood, CO

L. Simpson, et al., "New Discoveries in Soiling of PV Modules," 2018 PV Reliability Workshops, 2/27-3/1 Lakewood, CO

D. Miller, "PVQAT Task Group 12: The Contamination (Soiling) of Solar PV," 2018 PV Reliability Workshops, 2/27-3/1 Lakewood, CO

L. Micheli, "Panel Member on PV Soiling and Cleaning," Solar Asset Management, March 1314, 2018, San Francisco, CA 
G. Smestad, L. Micheli, T.A. Germer, and E.F. Fernández, "Optical Characterization of PV Glass Coupons and PV Modules Related to Soiling Losses," 4th Atlas/NIST Workshop on Photovoltaic Materials Durability, Gaithersburg, Maryland (December 2017)

L. Simpson, "November 2017 PVQAT 12 Webinar, "Key Themes of 2017 International PV Soiling Workshop in Dubai," November 14, 2017.

M. Muller, L. Micheli, and M. Deceglie, "Modeling to Reduce the Risk Associated with PV Soiling," 2017 International PV Soiling Workshop, October 23-25, Dubai, UAE.

M. Muller, D. Miller, and S. Toth, "Developing Abrasion Standards for PV Surfaces," 2017 International PV Soiling Workshop, October 23-25, Dubai, UAE.

L. Simpson, H. Mountinho, C. Perkins, C. S. Jiang, C. Weston, M. Al-Jassim, and M. Muller, "Soiling Mechanisms on PV Modules," 2017 International PV Soiling Workshop, October 2325, Dubai, UAE.

L. Micheli, M. Deceglie, and M. Muller "On seasonal soiling trends and their predictability," PVSC 2017.

M. Muller, L. Micheli, and A. Martinez-Morales, "A Method to Extract Soiling Loss Data from Soiling Stations with Imperfect Cleaning Schedules.” PVSC 2017.

M. Deceglie, L. Micheli, and M. Muller, "Quantifying Year-to-Year Variations in Solar Panel Soiling from PV Energy-Production Data." PVSC 2017.

L. Micheli et al., "A unified global investigation on the spectral effects of soiling losses of PV glass substrates: preliminary results." PVSC 2017.

C.L. Perkins, M. Muller, and L. Simpson, "Laboratory Studies of Particle Cementation and PV module Soiling." PVSC 2017.

L.J. Simpson, et al., "NREL Efforts to Address Soiling on PV Modules." PVSC 2017.

H.R. Moutinho, C.-S. Jiang, B. To, C. Perkins, M. Muller, M.M. Al-Jassim, and L. Simpson, "Investigation of Adhesion Forces Between Dust Particles and Solar Glass." PVSC 2017.

L. Micheli, M. Deceglie, and M. Muller "On seasonal soiling trends and their predictability," PV Reliability Workshop, 2017.

M. Muller, "Progress towards mapping out PV soiling losses in the U.S.," PV Reliability Workshop, 2017.

L. Simpson, H. Mountinho, C. Perkins, C.S. Jiang, M. Al-Jassim, and M. Muller "Adhesion Mechanisms for Soiling on PV Glass," PV Reliability Workshop, 2017.

M. Deceglie, L. Micheli, M. Muller, and S. Kurtz, "Calculating annual soiling loss from PV production data," PV Reliability Workshop 2017. 
M. Deceglie, L. Micheli, and M. Muller, "Quantifying soiling loss using PV energy production data," PVQAT TG12 Webinar 2017.

M. Muller, J. Gaglioti, and D. Young, "Panel discussion on PV soiling issues," North American Solar Asset Management Conference.

C. Perkins, "Surface science methods and their application to the study of module soiling," DuraMat meeting, 10/10/16-10/11/16.

C. Perkins, "Laboratory studies of particle cementation and PV module soiling," PV Quality Assurance Task Force, January 10, 2017.

M. Miller, "Capacity Building Workshop for Soiling Mitigation for Solar Energy and Innovations in Concentrating Solar Power at University of Florida"

M. Muller, “An Introduction to NREL Soiling Research Modeling," Soiling Effect on PV Modules Workshop Dubai, U.A.E.

M. Muller, "Soiling Losses and Extraction of Soiling Rates from PV Production Data," Soiling Effect on PV Modules Workshop Dubai, U.A.E.

M. Muller, "U.S.A. Perspective on PV Soiling " Soiling Effect on PV Modules Workshop Dubai, U.A.E.

L. Micheli, et al., "Determining the effects of environment and atmospheric parameters on onfield PV performance," PVSC2016.

M. Deceglie, et al., "A Scalable Method for Extracting Soiling Rates from PV Production Data," PVSC2016.

L. Simpson, "The Modeling of the Effects of Soiling, Its Mechanisms, and the Corresponding Abrasion," PV Module Reliability Workshop, 2016.

\section{References}

\footnotetext{
${ }^{1}$ L.J. Simpson, M. Muller, M. Deceglie, H. Moutinho, C. Perkins, C.S. Jiang, D.C. Miller, L. Micheli, G.

Tamizhmani, S.R.V. Tatapudi, M. Al-Jassim, S. Toth, NREL Efforts to Address Soiling on PV Modules; in: 2017 IEEE 44th Photovolt. Spec. Conf., IEEE, Washington, D.C., (2017).

${ }^{2}$ M.G. Deceglie, L. Micheli, M. Muller, Quantifying Soiling Loss Directly from PV Yield, IEEE J. Photovoltaics. (2018). doi:10.1109/JPHOTOV.2017.2784682.

${ }^{3}$ L. Micheli, M.G. Deceglie, Predicting Future Soiling Losses Using Environmental Data, in: 35th European Photovoltaic Solar Energy Conference and Exhibition, Bruxelles, Belgium, 2018, pp. 1-4.

${ }^{4}$ T. Sarver, A. Al-Qaraghuli, L.L. Kazmerski, A comprehensive review of the impact of dust on the use of solar energy: History, investigations, results, literature, and mitigation approaches, Renew. Sustain. Energy Rev. 22 (2013) 698-733. doi:10.1016/j.rser.2012.12.065.

${ }^{5}$ National Renewable Energy Laboratory, Photovoltaic modules soiling map, (2018). https://www.nrel.gov/pv/soiling.html (accessed May 18, 2018).
} 
${ }^{6}$ A. Kimber, L. Mitchell, S. Nogradi, H. Wenger, The Effect of Soiling on Large Grid-Connected Photovoltaic Systems in California and the Southwest Region of the United States, in: Photovolt. Energy Conversion, Conf. Rec. 2006 IEEE 4th World Conf., 2006: pp. 2391-2395.

${ }^{7}$ E.P. Roth, A.J. Anaya. Effect of natural soiling and cleaning on the size distribution of particles deposited on glass mirrors. Journal of Solar Energy Engineering 1980;102:248-56

${ }^{8}$ L.J. Simpson, M. Muller, M. Deceglie, H. Moutinho, C. Perkins, C.S. Jiang, et al., NREL Efforts to Address

Soiling on PV Modules, in: 2017 IEEE 44th Photovolt. Spec. Conf., IEEE, Washington, D.C., 2017.

${ }^{9}$ International Electrotechnical Commission, Photovoltaic system performance - Part 1: Monitoring (IEC 61724-1, Edition 1.0, 2017-03), (2017).

${ }^{10}$ M. Gostein, J.R. Caron, B. Littmann, Measuring soiling losses at utility-scale PV power plants, 2014 IEEE 40 th Photovolt. Spec. Conf. (2014) 0885-0890. doi:10.1109/PVSC.2014.6925056.

${ }^{11}$ M. Gostein, T. Duster, C. Thuman, Accurately Measuring PV Soiling Losses With Soiling Station Employing Module Power Measurements, in: IEEE 42nd Photovolt. Spec. Conf., 2015.

${ }^{12}$ M. Muller, L. Micheli, A.A. Martinez-Morales, A Method to Extract Soiling Loss Data From Soiling Stations with Imperfect Cleaning Schedules, in: 2017 IEEE 44th Photovolt. Spec. Conf., IEEE, Washington, D.C., 2017.

${ }^{13}$ See for example: M. Korevaar, J. Mes, P. Nepal, G. Snijders, X. van Mechelen, Novel Soiling Detection System for Solar Panels, in: 33rd Eur. Photovolt. Sol. Energy Conf. Exhib., Amsterdam, The Netherlands, n.d., pp. 23492351. M. Korevaar, J. Mes, A.A. Merrouni, T. Bergmans, X. Van Mechelen, Unique soiling detection system for PV modules, in: 36th Eur. Photovolt. Sol. Energy Conf. Exhib., Bruxelles, Belgium, 2018.

${ }^{14}$ See for example: M. Gostein, S. Faullin, K. Miller, J. Schneider, B. Stueve, in: 7th World Conf. Photovolt. Energy Convers., IEEE, Waikoloa, HI, 2018. M. Gostein, S. Faullin, K. Miller, J. Schneider, B. Stueve, in: 36th Eur.

Photovolt. Sol. Energy Conf. Exhib., Bruxelles, Belgium, 2018.

${ }^{15}$ G. TamizhMani, in: 2018 PV Reliability Workshop, Golden, Colorado, USA.

${ }^{16}$ F.A. Mejia, J. Kleissl, Soiling losses for solar photovoltaic systems in California, Sol. Energy. 95 (2013) $357-363$. doi:10.1016/j.solener.2013.06.028.

${ }^{17}$ L. Micheli, D. Ruth, M. Muller, Seasonal Trends of Soiling on Photovoltaic Systems, in: 2017 IEEE 44th Photovolt. Spec. Conf., IEEE, Washington, D.C., 2017.

${ }^{18}$ M. Gostein, K. Passow, M.G. Deceglie, L. Micheli, B. Stueve, Local Variability in PV Soiling Rate, in: IEEE (Ed.), 7th World Conf. Photovolt. Energy Convers., Waikoloa, HI, 2018.

${ }^{19}$ M.G. Deceglie, L. Micheli, M. Muller, Quantifying Year-to-Year Variations in Solar Panel Soiling from PV Energy-Production Data, in: 2017 IEEE 44th Photovolt. Spec. Conf., IEEE, Washington, D.C., 2017.

${ }^{20}$ L. Boyle, H. Flinchpaugh, M. Hannigan, Ambient airborne particle concentration and soiling of PV cover plates, 2014 IEEE 40th Photovolt. Spec. Conf. (2014). 3171-3173. doi:10.1109/PVSC.2014.6925609.

${ }^{21}$ National Renewable Energy Laboratory, PV_soiling: code for extracting soiling loss from PV plant data, (n.d.). https://github.com/NREL/pv_soiling.

${ }^{22}$ L. Micheli, M. Muller, S. Kurtz, Determining the effects of environment and atmospheric parameters on PV field performance, in: 2016 IEEE 43rd Photovolt. Spec. Conf., IEEE, Portland, OR, 2016: pp. 1724 - 1729.

doi:10.1109/PVSC.2016.7749919.

${ }^{23}$ M.G. Deceglie, M. Muller, Z. Defreitas, S. Kurtz, A Scalable Method for Extracting Soiling Rates from PV Production Data, in: 2016 IEEE 43rd Photovolt. Spec. Conf., 2016.

${ }^{24}$ L. Micheli, D. Ruth, M.G. Deceglie, M. Muller, Time Series Analysis of Photovoltaic Soiling Station Data:

Version 1.0, August 2017, Golden, CO, 2017. https://www.nrel.gov/docs/fy17osti/69131.pdf.

${ }^{25}$ L. Micheli, M.G. Deceglie, M. Muller, Mapping Photovoltaic Soiling Using Spatial Interpolation Techniques, IEEE J. Photovoltaics.

${ }^{26}$ L. Micheli, M. Muller, An investigation of the key parameters for predicting PV soiling losses, Prog. Photovoltaics Res. Appl. 25 (2017) 291-307. doi:10.1002/pip.2860.

${ }^{27}$ L. Micheli, M.G. Deceglie, M. Muller, Predicting photovoltaic soiling losses using environmental parameters: An update, Prog. Photovolt Res. Appl.

${ }^{28}$ National Renewable Energy Laboratory, National Solar Radiation Data Base (NSRDB), (n.d.).

https://nsrdb.nrel.gov/ (accessed May 18, 2018).

${ }^{29}$ D.L. King, W.E. Boyson, J.A. Kratochvill, Photovoltaic array performance model, Albuquerque, New Mexico, 2004. doi:10.2172/919131.

${ }^{30}$ H.R. Moutinho, C.-S. Jiang, B. To, C. Perkins, M. Muller, M.M. Al-Jassim, and L. Simpson, “Adhesion Mechanisms on Solar Glass - Effects of Relative Humidity, Roughness, and Particle Shape and Size." Solar Energy Materials and Solar Cells, 172, 145 (2017) 
${ }^{31}$ C.-S. jiang, H.R. Moutinho, B. To, C. Xiao, C. perkins, M. Muller, M.M. Al-Jassim, and L.J. Simpson, "Strong attraction and adhesion forces of dust particles by system voltages of photovoltaic modules", submitted to IEEE J. Photovoltaics.

${ }^{32}$ C. L. Perkins, "Molecular Anchors for Self-Assembled Monolayers on ZnO: A Direct Comparison of the Thiol and Phosphonic Acid Moieties," J. Phys. Chem. C, vol. 113, no. 42, pp. 18276-18286, Oct. 2009.

${ }^{33}$ J. N. D’Amour, J. J. R. Stålgren, K. K. Kanazawa, C. W. Frank, M. Rodahl, and D. Johannsmann, “Capillary Aging of the Contacts between Glass Spheres and a Quartz Resonator Surface," Phys. Rev. Lett., vol. 96, no. 5, p. 058301, Feb. 2006.

${ }^{34}$ B. Figgis, A. Ennaoui, S. Ahzi, and Y. Rémond, "Review of PV soiling particle mechanics in desert environments," Renew. Sustain. Energy Rev., vol. 76, pp. 872-881, Sep. 2017.

${ }^{35}$ L.L. Kazmerski et al., "Fundamental studies of the adhesion of dust to PV module chemical and physical relationships at the microscale," presented at the 2015 IEEE 42nd Photovoltaic Specialist Conference, PVSC 2015, 2015

${ }^{36}$ K. Ilse, M. Werner, V. Naumann, B. W. Figgis, C. Hagendorf, and J. Bagdahn, "Microstructural analysis of the cementation process during soiling on glass surfaces in arid and semi-arid climates," Phys. Status Solidi RRL Rapid Res. Lett. 10(7), 525-529, Jul. 2016

${ }^{37}$ E. Klimm, T. Kaltenbach, M. Koehl, M. Masche, D. Philipp, and K.-A. Weiss, "Soiling and Abrasion of Glazing Material and Mirrors in Extreme Climatic Conditions - Indoor and Outdoor Tests," Proc. Euro Weathering Symp. (2015).

${ }^{38}$ Z. Edfouf, M. Guerguer, O. Raccurt, "Glass and Polymeric Mirrors Ageing under different Moroccan Weathers, an Application for CSP Power Plants," Energy Proc., 69, 2015, 1508-1518.

${ }^{39}$ S. Bouaddi, A. Ihlal, A. Fernandez-García, "Comparative analysis of soiling of CSP mirror materials in arid zone", Renewable Energy 101, 2017, 437-449.

${ }^{40}$ T. Hirohata, Y. Ota, and K. Nishioka, "Anti-Soiling Coating Based on Silica for Fresnel Lens of Concentrator Photovoltaics," JJAP 54 (2015), 08KE09.

K. Nishioka, K. Ikematsu, Y. Ota, and K. Araki, "Sandblasting Durability of Acrylic and Glass Fresnel Lenses for Concentrator Photovoltaic Modules," Solar Energy 86 (2012): 3021-3025.

S.C. Pop, V. Abbaraju, B. Brophy, Y.S. Yang, S. Maghsoodi, and P. Gonsalves, "A Highly Abrasive-Resistant, Long-Lasting Anti-Reflective Coating for PV Module Glass,” Proc. IEEE PVSC (2014): 2715-2719.

${ }^{41}$ S. Toth, M. Muller, D.C. Miller, L. Simpson, H. Moutinho, B. To, and L. Micheli, "PV Soiling and Abrasion: Initial Observations From 5-Year Module Glass Coating Study," Solar Energy Materials and Solar Cells, Accepted (2018).

${ }^{42}$ A. Einhorn, L. Micheli, D.C. Miller, L.J. Simpson, M.T. Muller, S. Toth, J.J. John, A. Kottantharayil, and C. Engtrakul, "Optical microscopy study of soiling on PV glass: Evaluation of mitigation strategies", Proc. IEEE PVSC, Accepted (2018).

43 "Biological soiling" in L.G.W. Verhoef, Soiling and Cleaning of Buiilding Facades, Chapman and Hill: London, 1988.

${ }^{44}$ DIN 53778-2, Emulsion Paints for Interior Use; Evaluation of Cleanability and of Wash and Scrub Resistance of Coatings (Deutsches Institut für Normung, Berlin, 1983), 1-7.

ASTM D968, Standard Test Methods for Abrasion Resistance of Organic Coatings by Falling Abrasive (ASTM International, West Conshohocken, PA, 2015), 1-5.

${ }^{45}$ MIL-STD-810G, Test Method Standard for Environmental Engineering Considerations and Laboratory Tests [Test Method 510.5 Sand and Dust, (Blowing Sand)] (United States Department of Defense, 2003), 1-13.

${ }^{46}$ BS EN 1096-2, Glass in Building. Coated Glass. Requirements and Test Methods for Class A, B and S Coatings (British Standards Institution, London, 2012), 1-34.

ASTM D2486 Standard Test Methods for Scrub Resistance of Wall Paints (ASTM International, West Conshohocken, PA, 2012), 1-4.

DIN 53778-2, Emulsion Paints for Interior Use; Evaluation of Cleanability and of Wash and Scrub Resistance of Coatings (Deutsches Institut für Normung, Berlin, 1983), 1-7.

${ }^{47}$ D.C. Miller, M.T. Muller, and L.J. Simpson, Review of Artificial Abrasion Test Methods for PV Module Technology, NREL/TP-5J00-66334, 2016, 1-25.

${ }^{48}$ F. Buckel, "Plastic Glazing - Scratch and Abrasion Tests," Proc. IGPG Meeting, 2011.

${ }^{49}$ ASTM C778, Standard Specification for Standard Sand (ASTM International, West Conshohocken, PA, 2013), $1-3$.

${ }^{50}$ ASTM D968, Standard Test Methods for Abrasion Resistance of Organic Coatings by Falling Abrasive (ASTM International, West Conshohocken, PA, 2015), 1-5. 
${ }^{51}$ ISO 12103-1, Road Vehicles - Test Dust for Filter Evaluation - Part 1: Arizona Test Dust (International Organization for Standardization: Geneva, 1997), 1-9.

${ }^{52}$ MIL-STD-810G, Test Method Standard for Environmental Engineering Considerations and Laboratory Tests [Test Method 510.5 Sand and Dust, (Blowing Sand)] (United States Department of Defense, 2003), 1-13.

${ }_{53}^{5}$ L. Micheli, J.A. Caballero, E.F. Fernandez, G.P. Smestad, G. Nofuentes, T.K. Mallick, et al., Waveband investigation on the impact of soiling on various photovoltaic technologies, Sol. Energy Mater. Sol. Cells. 